\title{
An Etiological Foxp2 Mutation Impairs Neuronal Gain in Layer VI Cortico-Thalamic Cells through Increased $\mathrm{GABA}_{\mathrm{B}} / \mathrm{GIRK}$ Signaling
}

\author{
Mélanie Druart, ${ }^{1,2,3}$ Matthias Groszer, ${ }^{1,2,3}$ and ${ }^{\mathbb{C}}$ Corentin Le Magueresse ${ }^{1,2,3}$ \\ ${ }^{1}$ Institut National de la Santé et de la Recherche Médicale Unité Mixte de Recherche-S 1270, Paris 75005, France, ${ }^{2}$ Sorbonne Université, Paris \\ 75005, France, and ${ }^{3}$ Institut du Fer à Moulin, Paris 75005, France
}

A rare mutation affecting the Forkhead-box protein P2 (FOXP2) transcription factor causes a severe monogenic speech and language disorder. Mice carrying an identical point mutation to that observed in affected patients (Foxp2 ${ }^{+/ R 552 \mathrm{H}}$ mice) display motor deficits and impaired synaptic plasticity in the striatum. However, the consequences of the mutation on neuronal function, in particular in the cerebral cortex, remain little studied. Foxp2 is expressed in a subset of Layer VI cortical neurons. Here, we used Ntsr1-EGFP mice to identify Foxp2+ neurons in the mouse auditory cortex ex vivo. We studied the functional impact of the $\mathrm{R} 552 \mathrm{H}$ mutation on the morphologic and functional properties of Layer VI cortical neurons from Ntsr1-EGFP; Foxp2 ${ }^{+/ R 552 \mathrm{H}}$ male and female mice. The complexity of apical, but not basal dendrites was significantly lower in Foxp2 ${ }^{+/ R 552 H}$ cortico-thalamic neurons than in control Foxp2 ${ }^{+/+}$neurons. Excitatory synaptic inputs, but not inhibitory synaptic inputs, were decreased in Foxp2 $2^{+/ R 552 H}$ mice. In response, homeostatic mechanisms would be expected to increase neuronal gain, i.e., the conversion of a synaptic input into a firing output. However, the intrinsic excitability of Foxp2 + cortical neurons was lower in Foxp2 ${ }^{+/ R 552 H}$ neurons. A-type and delayed-rectifier (DR) potassium currents, two putative transcriptional targets of Foxp2, were not affected by the mutation. In contrast, $\mathrm{GABA}_{\mathrm{B}} / \mathrm{GIRK}$ signaling, another presumed target of Foxp2, was increased in mutant neurons. Blocking GIRK channels strongly attenuated the difference in intrinsic excitability between wild-type (WT) and Foxp2 ${ }^{+/ R 552 \mathrm{H}}$ neurons. Our results reveal a novel role for Foxp2 in the control of neuronal input/output homeostasis.

Key words: auditory cortex; excitability; language; patch-clamp; speech; synapses

Significance Statement

Mutations of the Forkhead-box protein 2 (FOXP2) gene in humans are the first known monogenic cause of a speech and language disorder. The Foxp2 mutation may directly affect neuronal development and function in neocortex, where Foxp2 is expressed. Brain imaging studies in patients with a heterozygous mutation in FOXP2 showed abnormalities in cortical languagerelated regions relative to the unaffected members of the same family. However, the role of Foxp2 in neocortical neurons is poorly understood. Using mice with a Foxp2 mutation equivalent to that found in patients, we studied functional modifications in auditory cortex neurons ex vivo. We found that mutant neurons exhibit alterations of synaptic input and GABAB/GIRK signaling, reflecting a loss of neuronal homeostasis.

Received 0ct. 31, 2019; revised Sep. 15, 2020; accepted Sep. 18, 2020

Author contributions: M.D., M.G., and C.L.M. designed research; M.D. and C.L.M. performed research; M.D. and C.L.M. analyzed data; C.L.M. wrote the paper.

M.D. was the recipient of a PhD fellowship from the Doctoral School "Brain-Cognition-Behavior" (Sorbonne Université) and of a PhD fellowship from Fondation pour la Recherche Médicale (FRM FDT201904008029). This work was supported by an ATIP/AVENIR grant (M.G.) and by starting funds from Institut National de la Santé et de la Recherche Médicale and by the Marie Curie Career Integration Grant from the European Union 334592 (to C.L.M.). We thank Rebecca Piskorowski for valuable comments on the manuscript, Dorthe Kaufhold for her help with morphological reconstructions, Vincent Robert for providing custom-made procedures for Igor Pro and Thierry Gallopin for granting access to the Neurolucida system at ESPCI.

The authors declare no competing financial interests.

Correspondence should be addressed to Corentin Le Magueresse at corentin.le-magueresse@inserm.fr.

https://doi.org/10.1523/JNEUROSCI.2615-19.2020

Copyright $\odot 2020$ the authors

\section{Introduction}

The identification of mutations and disruptions of FOXP2, the gene coding for the Forkhead-box protein P2 transcription factor, has provided the first example of a gene specifically implicated in a speech and language disorder, initially in the multigenerational KE family. Here, around half the members carry a heterozygous FOXP2 mutation which is inherited in an autosomal dominant manner (Lai et al., 2001). The mutation yields an arginine-to-histidine substitution $(\mathrm{R} 553 \mathrm{H})$ that disturbs the DNA-binding domain of the encoded transcription factor, thereby abolishing transcriptional repression (Lai et al., 2001; Vernes et al., 2006). Affected individuals suffer from developmental verbal dyspraxia, i.e., have difficulty mastering the rapid 
orofacial motor sequences necessary for fluent speech (Watkins et al., 2002; Vargha-Khadem et al., 2005). Speech deficits are accompanied by other expressive and receptive deficits in both oral and written language in affected members of the KE family (Watkins et al., 2002). It has long been suggested that critical roles of FOXP2 might lie further upstream than the motor system (Vargha-Khadem et al., 2005). Remarkably, fMRI studies revealed that the members of the KE family show significant cortex underactivation relative to the unaffected members in Broca's area and its right homolog, as well as in other cortical languagerelated regions and in the putamen (Liégeois et al., 2003). The Foxp2 protein sequence is highly similar in many vertebrate species (Enard et al., 2002), and is expressed in comparable regions of the brain (Ferland et al., 2003; Haesler et al., 2004; Teramitsu et al., 2004). This conservation pattern might allow using mouse models to study ancestral neuronal circuits which potentially have been recruited during language evolution (Scharff and Petri, 2011; French and Fisher, 2014). In mice, Foxp2 expression is found prominently in cortical Layer VI, striatal medium spiny neurons, thalamus and cerebellar Purkinje cells. Expression starts during mid-embryogenesis and is maintained in the adult brain suggesting roles in both neuronal development and function (Ferland et al., 2003). Based on expression pattern and functional studies, it has been proposed that Foxp2 in common vertebrate ancestors plays important roles in development and/or function of cortico-striatal, cerebello-cortical and thalamo-cortical circuits influencing, in particular, sensory-motor processing (VarghaKhadem et al., 2005; French et al., 2019). We previously generated a knock-in mouse line carrying an identical mutation to that of the KE family in the mouse homolog of the human FOXP2 gene (R552H; Groszer et al., 2008). Homozygous mutants display strong motor impairment and die around three weeks after birth. Heterozygous mutants show motor-skill deficits and altered vocalizations, and field potential recordings revealed impaired long-term depression at striatal glutamatergic inputs (Groszer et al., 2008). Furthermore, transgenic mice carrying the $\mathrm{R} 552 \mathrm{H}$ mutation or other loss-of-function mutations in Foxp2 display decreased excitatory inputs and increased inhibitory inputs onto striatal medium spine neurons (Chen et al., 2016; van Rhijn et al., 2018). While Foxp2 plays a limited role on corticogenesis (Kast et al., 2019), the impact of Foxp2 mutations on neuronal development and function remains little studied. In particular, the role of Foxp2 in cortical neurons is largely unknown. Here, we studied the impact of the KE family mutation on the morphology and electrophysiological properties of Foxp2-expressing (Foxp2+) neurons in the auditory cortex. We focused on the auditory cortex for three main reasons. First, auditory feedback is crucial for language learning (Tallal et al., 1996; Kuhl, 2010). Second, Foxp2 mutations in mice impair auditory processing and auditory-motor association learning (Kurt et al., 2009). Third, the structure of the auditory cortex is highly conserved across mammals which makes it well suited to study mouse models of Foxp2-associated disorders (Ehret, 1997; Kaas, 2005). We show that the R552H mutation affects neuronal morphology, reduces excitatory inputs and decreases neuronal excitability through $\mathrm{GABA}_{\mathrm{B}} / \mathrm{GIRK}$ signaling, reflecting the loss of several homeostatic checkpoints in Foxp2+ Layer VI cortico-thalamic neurons.

\section{Materials and Methods}

Animals

We used transgenic Ntsr1-EGFP::Foxp2 ${ }^{+/ R 552 H}$ mice of either sex resulting from the cross of Ntsr1-EGFP (Tg(Ntsr1-EGFP/Rpl10a)TS16Htz;
Doyle et al., 2008) and Foxp2 $2^{+/ R 552 \mathrm{H}}$ mice. Animal care and procedures were according to local and international regulations for the use of experimental animals.

\section{Immunohistochemistry}

Juvenile Ntsr1-EGFP::Foxp2 ${ }^{+/+}$mice (age P35) were anesthetized with pentobarbital and intracardially perfused with Roti-Histofix 4\% (Carl Roth). The brains were removed and fixed overnight in Roti-Histofix. $50-\mu \mathrm{m}$ sections were cut using a vibratome (Leica VT1000S). Free-floating sections were permeabilized and blocked in $0.2 \%$ Triton X-100-PBS, $3 \%$ BSA-PBS for 60 min before incubation with the first antibody in $0.2 \%$ Triton X-100, 3\% BSA-PBS overnight at $4^{\circ} \mathrm{C}$. After three washes in PBS, sections were incubated with the secondary antibody in PBS for $2 \mathrm{~h}$, washed again in PBS, and mounted. Primary antibodies were: goat antiFoxp2 (1:500, Santa Cruz), rabbit anti-GFP (1:1000, Sigma). Secondary antibodies were: anti-goat Cy3 (1:250, Jackson ImmunoResearch), antirabbit Alexa Fluor 488 (1:1000, Invitrogen). The sections were analyzed by confocal microscopy (Leica SP5). Colocalization was determined on maximal intensity projections from seven coronal sections (three different mice) using the ImageJ Cell Counter plug-in. A total of 909 EGFP+ cells and 1064 Foxp2+ cells were included in the colocalization analysis.

\section{Acute slice preparation}

We prepared $250-\mu \mathrm{m}$-thick coronal slices from brains of Ntsr1-EGFP:: Foxp2 $2^{+/ R 552 H}$ mice and control Ntsr1-EGFP::Foxp2 $2^{+/+}$littermates. Animals were deeply anesthetized with sodium pentobarbital $(150 \mathrm{mg} /$ $\mathrm{kg})$ and perfused transcardially with ice-cold $\left(0-4^{\circ} \mathrm{C}\right)$ oxygenated $(95 \%$ $\mathrm{O}_{2}-5 \% \mathrm{CO}_{2}$ ) solution containing the following: $110 \mathrm{~mm}$ choline chloride, $2.5 \mathrm{~mm} \mathrm{KCl}, 25 \mathrm{~mm}$ glucose, $25 \mathrm{~mm} \mathrm{NaHCO}_{3}, 1.25 \mathrm{~mm} \mathrm{NaH}_{2} \mathrm{PO}_{4}, 0.5$ $\mathrm{mM} \mathrm{CaCl}_{2}, 7 \mathrm{~mm} \mathrm{MgCl}_{2}, 11.6 \mathrm{~mm} \mathrm{~L}$-ascorbic acid, and $3.1 \mathrm{~mm}$ sodium pyruvate. The brain was extracted and acute coronal slices were cut in the same ice-cold solution using a vibroslicer (HM $650 \mathrm{~V}$, Microm), then stored in artificial CSF (ACSF) containing the following: $125 \mathrm{~mm}$ $\mathrm{NaCl}, 2.5 \mathrm{~mm} \mathrm{KCl}, 25 \mathrm{~mm}$ glucose, $25 \mathrm{~mm} \mathrm{NaHCO}_{3}, 1.25 \mathrm{~mm} \mathrm{NaH}_{2} \mathrm{PO}_{4}$, $2 \mathrm{mM} \mathrm{CaCl}_{2}$, and $1 \mathrm{mM} \mathrm{MgCl}_{2}$, continuously bubbled with $95 \% \mathrm{O}_{2}-5 \%$ $\mathrm{CO}_{2}$. Slices were incubated in ACSF at $32^{\circ} \mathrm{C}$ for $20 \mathrm{~min}$ and then at room temperature $\left(20-25^{\circ} \mathrm{C}\right)$. For patch-clamp recordings, slices were transferred to the recording chamber where they were continuously superfused with ACSF $\left(30-32^{\circ} \mathrm{C}\right)$ containing the following: $125 \mathrm{~mm}$ $\mathrm{NaCl}, 3.5 \mathrm{~mm} \mathrm{KCl}, 1 \mathrm{~mm} \mathrm{CaCl}, 0.5 \mathrm{~mm} \mathrm{MgCl}_{2}, 1.25 \mathrm{~mm} \mathrm{NaH}_{2} \mathrm{PO}_{4}, 25$ $\mathrm{mm} \mathrm{NaHCO}$, and $25 \mathrm{~mm}$ glucose ( $\mathrm{pH} 7.2$, maintained by continuous bubbling with $95 \% \mathrm{O}_{2}-5 \% \mathrm{CO}_{2}$ ). In some experiments, $3.5 \mathrm{mM} \mathrm{KCl}$ was changed to $1.5 \mathrm{~mm} \mathrm{KCl}$ as indicated in the text.

\section{Electrophysiology}

Patch-clamp pipettes (4- to 6-M $\Omega$ resistance) were prepared from borosilicate glass (BF150-86-10; Harvard Apparatus) using a DMZ pipette puller (Zeitz).

Current-clamp and voltage-clamp recordings were performed using an EPC-10 amplifier (HEKA Elektronik) using the following intracellular solution: $105 \mathrm{~mm}$ K-gluconate, $10 \mathrm{~mm}$ HEPES, $10 \mathrm{~mm}$ phosphocreatine- $\mathrm{Na}, 4 \mathrm{~mm}$ ATP- $\mathrm{Na}_{2}$, and $30 \mathrm{~mm} \mathrm{KCl} \mathrm{(pH} \mathrm{7.25,} \mathrm{adjusted} \mathrm{with}$ $\mathrm{KOH}$ ). To record miniature EPSCs (mEPSCs) and evoked EPSCs (eEPSCs), the following intracellular solution was used: $120 \mathrm{~mm}$ Csmethane sulfonate, $10 \mathrm{~mm} \mathrm{CsCl}, 10 \mathrm{~mm}$ HEPES, $10 \mathrm{~mm}$ phosphocreatine, 0.2 mм EGTA, 8 mм NaCl, 2 mм ATP-Na2, and 3 mм QX 314 (pH 7.25, adjusted with $\mathrm{CsOH}$ ).

Input resistance (Rinput) and membrane capacitance $(\mathrm{Cm})$ were measured using a 10-mV hyperpolarizing step from a holding potential of $-65 \mathrm{mV}$ (mean of three repeats, $50 \mathrm{~ms}$ in duration). Cm was obtained by single exponential fitting of the current decay.

mEPSCs were recorded at a holding potential of $-70 \mathrm{mV}$ in the presence of tetrodotoxin (TTX; $0.5 \mu \mathrm{M}$, Hello Bio) and SR95531 hydrobromide (GABAzine, $10 \mu \mathrm{M}$, Hello Bio). eEPSCs were recorded at a holding potential of $-70 \mathrm{mV}$ and triggered at a frequency of $0.1 \mathrm{~Hz}$ in the presence of GABAzine $(10 \mu \mathrm{M})$ with a monopolar electrode connected to a constant current stimulator (ISO-Flex, A.M.P.I.), positioned in Layer VI $\sim 100 \mu \mathrm{m}$ away from the recorded neuron. At least 12 consecutive sweeps were acquired and averaged for each experimental condition. To 
record miniature IPSCs (mIPSCs), we used an intracellular solution containing the following: $60 \mathrm{~mm}$ Cs methane sulfate, $70 \mathrm{~mm} \mathrm{CsCl}, 10 \mathrm{~mm}$ HEPES, $10 \mathrm{~mm}$ phosphocreatine, $0.2 \mathrm{~mm}$ EGTA, $8 \mathrm{~mm} \mathrm{NaCl}$, and $2 \mathrm{~mm}$ ATP-Mg (pH 7.25, adjusted with $\mathrm{CsOH}$ ). mIPSCs were recorded at a holding potential of $-70 \mathrm{mV}$ in the presence of TTX $(0.5 \mu \mathrm{M}$, Hello Bio), 6-cyano-7-nitroquinoxaline-2,3-dione (CNQX; $10 \mu \mathrm{M}$, Biotrend), and D-2-amino-5-phosphonopentanoic acid (D-APV; $50 \mu \mathrm{M}$, Hello Bio). Delayed-rectifier (DR) potassium channels were blocked with tetraethylammonium (TEA; 5 mm, Hello Bio) or tertiapin Q (100 nM, Hello Bio). GIRK-mediated currents were blocked with barium chloride (100 $\mu \mathrm{M}$, Sigma). Recordings of potassium channel-mediated currents were performed in the presence of $10 \mu \mathrm{M}$ CNQX, $50 \mu \mathrm{M}$ D-APV, and $10 \mu \mathrm{M}$ GABAzine to block synaptic activity, $0.5 \mu \mathrm{M}$ TTX to block voltage-gated sodium channels, and $50 \mu \mathrm{M} \mathrm{CdCl}_{2}$ to block voltage-gated calcium channels. We used CGP 54626 (10 $\mu \mathrm{m}$, Tocris) and CGP 55845 (10 $\mu \mathrm{M}$, Hello Bio) to block $\mathrm{GABAB}$ receptors.

Data acquisition and analysis

Stimulus delivery and data acquisition were performed using Patchmaster software (Heka Elektronik). The junction potentials $(-14.9 \mathrm{mV}$ for Csbased intracellular solutions and $-5 \mathrm{mV}$ for the $\mathrm{K}^{+}$-based intracellular solution) were uncorrected. Signals were sampled at $20 \mathrm{kHz}$ and filtered at $4 \mathrm{kHz}$. Offline analysis was performed using Clampfit (Molecular Devices) and Igor Pro (Wavemetrics). For the analysis of miniature PSCs, recordings were filtered offline at $2 \mathrm{kHz}$ and analyzed using MiniAnalysis (Synaptosoft). Series resistance was left uncompensated. Series resistance, and Rinput were monitored by voltage steps of $-10 \mathrm{mV}$. Experiments were discarded if the series resistance changed by $>25 \%$ during the recording.

The paired-pulse ratio (PPR) of evoked synaptic currents was calculated as the mean amplitude of the synaptic response evoked by the second stimulation over that evoked by the first stimulation.

Action potential (AP) parameters were measured using the first AP of the voltage response to a $140 \mathrm{pA}$-depolarizing current injection. The AP threshold was calculated using a second derivative method i.e., by measuring the membrane potential $\mathrm{V}$ when its second derivative $\mathrm{d}^{2} \mathrm{~V} /$ $\mathrm{dt}^{2}$ crosses $5 \%$ of the maximum $\mathrm{d}^{2} \mathrm{~V} / \mathrm{dt}^{2}$ (Meeks and Mennerick, 2007). AP amplitude was defined as the peak voltage of the AP minus the threshold. AP half-width was measured at the half-height of the AP rising phase.

For calculating DR and A-type voltage-gated potassium channelmediated currents $\left(I_{D R}\right.$ and $\left.I_{A}\right)$, leak subtraction was performed as follows: the current response to the first step of the family of depolarizing voltage command steps was scaled for each step of the family, and subtracted offline. This method was chosen over the classical $\mathrm{p} / \mathrm{n}$ leak subtraction which is more sensitive to changes in inward-rectifying potassium (e.g., GIRK) channel expression in Foxp2 ${ }^{+/ R 552 H}$ versus WT neurons. $I_{A}$ was measured in the presence of TEA $5 \mathrm{~mm}$ to block DR currents. TEA reduced but did not eliminate the slowly decaying component of voltage-gated potassium currents, as previously reported for Layer V pyramidal cells (Bekkers, 2000). Therefore, $I_{A}$ was measured for each voltage step by subtracting the residual $I_{D R}$ (defined as the average residual current measured from 100 to $140 \mathrm{~ms}$ after the beginning of the depolarizing step) to the peak current.

To measure baclofen-induced currents, changes in holding currents in response to bath application of baclofen $(100 \mu \mathrm{M})$ were recorded at $-65 \mathrm{mV}$ every $2 \mathrm{~s}$. The plotted values correspond to the difference between the baseline (average of 60 sweeps immediately before baclofen application) and the plateau response (average of 60 sweeps, starting 1 min after baclofen application).

Data are presented as mean \pm SEM. Statistical analyses were performed using Prism (GraphPad). The normality of data distribution was tested using Shapiro-Wilk's test. Unpaired two-tailed $t$ tests (for normally distributed datasets) or Mann-Whitney tests (for non-normally distributed datasets) were used for comparisons between two groups. For multiple comparisons we used two-way ANOVA followed by Sidak's test. Values of $p<0.05$ were considered statistically significant.

\section{Morphologic reconstructions}

Brain slices of mice aged postnatal day (P) 23-P35 were prepared as described for electrophysiology. Neurons were patch-clamped for 10-
30 min with biocytin $\left(2 \mathrm{mg} / \mathrm{ml}\right.$ in $\mathrm{K}^{+}$-based intracellular solution) in the patch pipette. After the pipette was withdrawn, slices were kept in the recording chamber for an additional $10 \mathrm{~min}$ and immersion-fixed in RotiHistofix $4 \%$ (Carl Roth) for $12-20 \mathrm{~h}$ at $4^{\circ} \mathrm{C}$. Biocytin-filled cells were permeabilized in Triton X-100 $1 \%$ for $1 \mathrm{~h}$, incubated with peroxidase-avidin-biotin complex (ABC; Vector Laboratories) for $2 \mathrm{~h}$ and visualized with DAB (Sigma-Aldrich). Subsequently, slices were mounted onto microscope slides and coverslipped with Mowiol. Morphologic reconstructions and Sholl analysis were performed with the Neurolucida 3D reconstruction system and the NeuroExplorer Software package (MicroBrightField). The experimenter was blind to the genotype of the mouse from which slices were obtained.

\section{Dendritic spine analysis}

Neurons were filled with biocytin $\left(2 \mathrm{mg} / \mathrm{ml}\right.$ in $\mathrm{K}^{+}$-based intracellular solution) through the patch pipette as for morphologic reconstructions. Biocytin-filled cells were permeabilized in Triton X-100 1.25\% and incubated with streptavidin-Cy3 (Sigma, 1:100) for $90 \mathrm{~min}$. Slices were mounted onto microscope slides and coverslipped with Fluoromount (Sigma-Aldrich). Confocal 3D image stacks of primary and secondary apical dendrites were taken at a distance of $80 \mu \mathrm{m}$ from the soma using a confocal microscope (SP5, Leica). Spine density was measured from maximal intensity projections using ImageJ. The experimenter was blind to the genotype.

\section{Results}

The vast majority of Foxp2+ neurons in neocortex are located in Layer VI. However, the lack of mice expressing fluorescent proteins under the control of the Foxp2 promoter precludes the identification of Foxp2+ neurons ex vivo in acute brain slices. The Ntsr1 promoter has been shown to drive transgene expression in nearly all Foxp $2^{+}$Layer VI neurons (Sundberg et al., 2018). We recently reported the co-expression of EGFP and Foxp2 in the cortex of mice expressing the EGFP-L10a transgene under the control of the Ntsr1 promoter (Ntsr1-EGFP mice; Doyle et al., 2008; Medvedeva et al., 2019). To confirm that EGFP expression in Ntsr1-EGFP mice may enable the identification of Foxp $2+$ neurons in the auditory cortex, we performed immunostainings for EGFP and Foxp 2 in brain slices from Ntsr1-EGFP mice. EGFP and Foxp2 strongly co-localized in Layer VI of all cortical areas that were examined including auditory cortex (Fig. $1 A-C$ ). Thus, in the auditory cortex, $95.9 \pm 1.1 \%$ of EGFP + Layer VI neurons expressed Foxp2. Conversely, $81.7 \pm 2.3 \%$ of Foxp $2+$ neurons expressed EGFP (Fig. 1D). These results indicate that EGFP expression in the Ntsr1-EGFP mouse cortex allows the identification and electrophysiological recording of Foxp $2+$ cortical neurons ex vivo. Next, we crossed Ntsr1-EGFP mice and Foxp2 $2^{+/ R 552 H}$ mice to study the impact of the R552H mutation on the morpho-functional properties of Foxp $2+$ neurons in the auditory cortex. We will henceforth refer to Ntsr1-EGFP:: Foxp $2^{+1+}$ mice as wild-type (WT) mice and to Ntsr1-EGFP:: Foxp $2^{+/ R 552 H}$ mice as Foxp $2^{+/ R 552 H}$ or mutant mice.

In neocortex, Layer VI pyramidal cells are subdivided into cortico-thalamic and corticocortical neurons. Cortico-thalamic neurons are upright pyramidal cells with an apical dendrite extending up to Layer IV, and sometimes Layers II-III and I. Corticocortical neurons constitute the other main excitatory neuron subtype. Their dendritic morphologies comprise inverted pyramids, bipolar cells and short upright pyramids. Their dendrites arborize locally, rarely extending beyond Layer $\mathrm{V}$ (Thomson, 2010). To study the anatomy of Foxp $2+$ neurons in cortical Layer VI, we patch-clamped EGFP+ neurons in acute auditory cortex slices from juvenile (P27-P35) WT mice. 
Patched neurons were filled with biocytin through the patch pipette before streptavidin-mediated staining and morphologic reconstruction. The apical dendrite of biocytin-filled neurons extended at least up to Layer IV, and often beyond Layer IV, a characteristic feature of cortico-thalamic projection neurons (Thomson, 2010; Fig. $2 A)$. This is consistent with previous studies showing that cortico-thalamic projecting cells in Layer VI of the primary visual cortex express Ntsr1 (Gong et al., 2007; Vélez-Fort et al., 2014) and that Foxp2 expression is restricted to Ntsr1-cre-expressing neurons in the visual and somatosensory cortices (Tasic et al., 2016; Sundberg et al., 2018; Kast et al., 2019). Thus, Layer VI Foxp2+ neurons in the auditory cortex are mostly cortico-thalamic projection neurons. We next examined the morphology of EGFP+ neurons from WT and Foxp $2^{+/ R 552 H}$ mice. In both genotypes apical dendrite length varied across cells, without clearly distinguishing discrete subopulations. Gross neuronal morphology did not differ between WT and Foxp $2^{+/ R 552 H}$ neurons (Fig. 2A), but the total length of the apical dendritic arbor was diminished in Foxp2 $2^{+/ R 552 H}$ neurons (WT: $n=17$ cells from 5 mice; Foxp2 $2^{+/ \mathrm{R} 552 \mathrm{H}}: n=18$ cells from four mice; apical, WT: $1947 \pm 180 \mu \mathrm{m}$, Foxp $2^{+/ R 552 H}$ : $1427 \pm 156 \mu \mathrm{m}, t$ test $p=0.036$; basal, WT: $776 \pm 136 \mu \mathrm{m}, \quad$ Foxp $2^{+/ \mathrm{R} 552 \mathrm{H}}: \quad 794 \pm 127$ $\mu \mathrm{m}, t$ test $p=0.92$ ). Sholl analysis revealed that apical dendrites in Foxp2 mutants had fewer intersections at individual Sholl radii than the corresponding dendrites in WT controls, indicating decreased dendrite complexity [two-way repeated-measures (RM) ANOVA, genotype effect: $F_{(1,33)}=$ 7.87, $p=0.0084$; Fig. $2 B$ ]. The complexity of basal dendrites was not affected by the mutation (two-way RM ANOVA, genotype effect: $F_{(1,33)}=0.00072, p=0.98$; Fig. $\left.2 B\right)$. In

addition, the apical dendritic branches of Foxp $2^{+/ \mathrm{R} 552 \mathrm{H}}$ neurons were shorter, while the length of basal dendrites remained unchanged (two-way RM ANOVA, genotype effect, apical: $F_{(1,33)}$ $=4.79, p=0.036$; basal: $F_{(1,33)}=0.0091, p=0.92$; Fig. $\left.2 C\right)$. These data show that the heterozygous $\mathrm{R} 552 \mathrm{H}$ mutation decreases the length and complexity of apical dendrites in Layer VI corticothalamic neurons.

The processing of information by cortical pyramidal neurons is determined by the timing, frequency and amplitude of synaptic inputs, and by neuronal gain, i.e., the conversion of synaptic inputs into a firing output. To identify the neuronal functions compromised in the cortex of Foxp $2^{+/ R 552 \mathrm{H}}$ mice, we examined synaptic transmission and intrinsic excitability, i.e., the propensity of a neuron to fire APs when subjected to an input current, in Foxp2+ neurons of the auditory cortex ex vivo.

We first focused on excitatory synapses. We examined spontaneous synaptic activity in Foxp $2+$ neurons from WT and Foxp $2^{+/ R 552 H}$ mice in the presence of TTX to block APmediated synaptic transmission. The frequency of mEPSCs was strongly reduced in Foxp $2^{+/ R 552 H}$ neurons while the amplitude of mEPSCs was unchanged (frequency, WT: $0.68 \pm 0.07 \mathrm{~Hz}$, Foxp2 $2^{+/ R 552 \mathrm{H}}: 0.37 \pm 0.05 \mathrm{~Hz}$, Mann-Whitney test, $p=0.0026$; amplitude, $t$ test, $p=0.42$; WT: $n=16$ cells from 4 mice; Foxp2 $2^{+/ R 552 H}: n=13$ cells from 3 mice; Fig. $3 A$, $B)$. Changes in mEPSC frequency may reflect presynaptic changes in the probability of neurotransmitter release, or a decreased number of synaptic contacts. Layer VI cortico-thalamic neurons receive most of their excitatory synaptic inputs from Layer IV and Layer V (Thomson, 2010), where Foxp2 is little or not expressed, suggesting that release probability changes may be unlikely to cause the strong decrease in mEPSC frequency that we observed in Foxp $2^{+/ R 552 \mathrm{H}}$ neurons. However, Foxp2 is also expressed in the thalamus (Ferland et al., 2003) and thalamo-cortical axons project onto Layer VI pyramidal neurons (Thomson, 2010), raising the possibility that presynaptic changes in the release probability might contribute to mEPSC frequency changes. In order to assess presynaptic changes in the release probability we measured the PPR of evoked synaptic currents. The PPR was similar in mutant and 


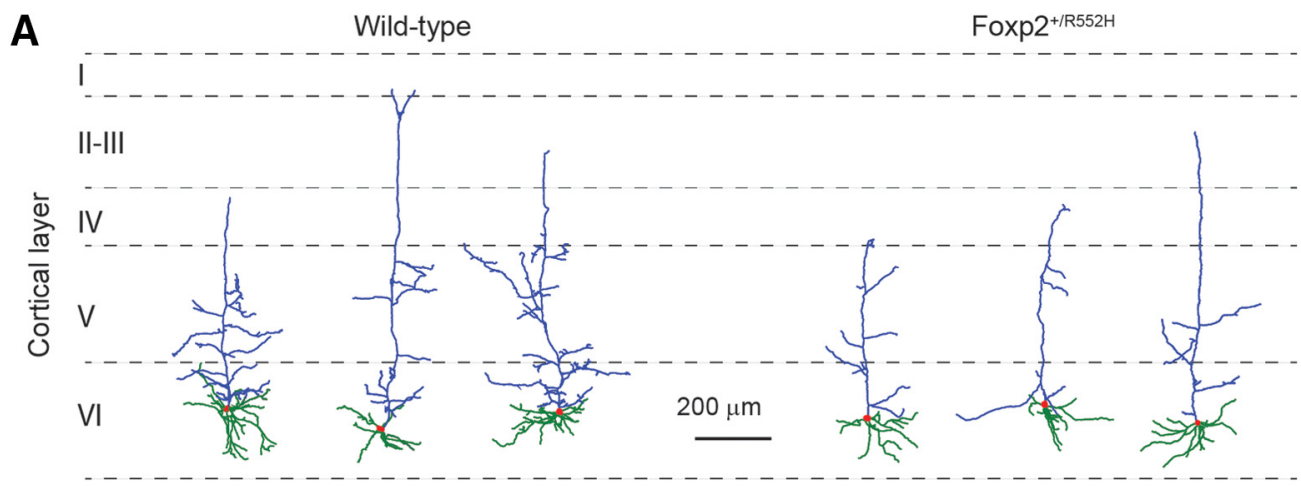

B
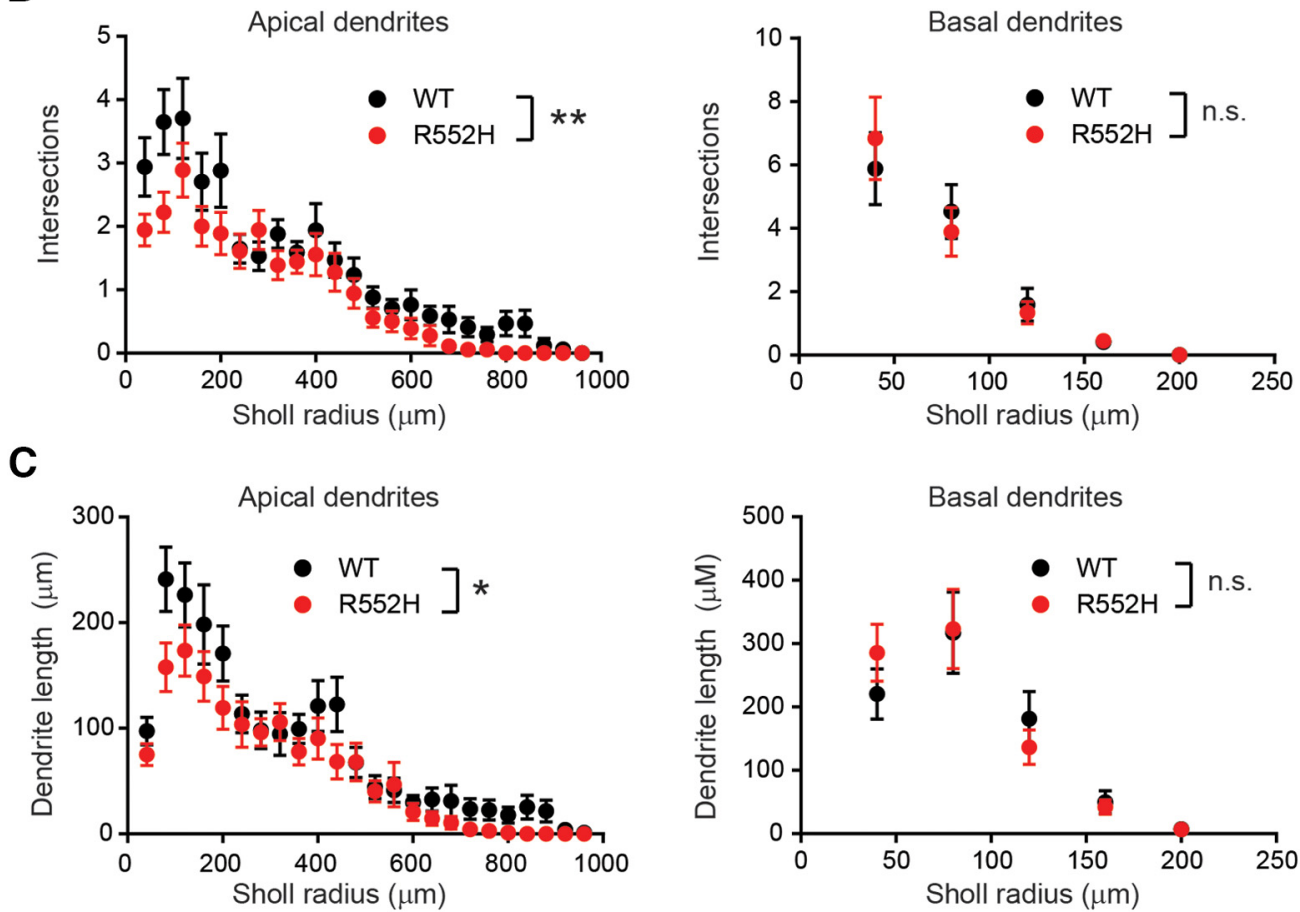

Figure 2. Sholl analysis demonstrating decreased apical dendrite arborization of Foxp2 $2^{+/ R 552 H}$ cortical neurons. $A$, Representative examples of the dendritic trees of control and Foxp2 ${ }^{+/ R 552 H}$ neurons. The apical dendrite is in blue, basal dendrites are in green. $\boldsymbol{B}, \boldsymbol{C}$, Sholl analysis of auditory cortex neurons showing less complex dendritic arbor $(\boldsymbol{B})$ and decreased length of apical dendrite branches $(C)$ in Foxp2 ${ }^{+/ R 552 H}$ neurons; ${ }^{* *}$ two-way RM ANOVA, genotype effect, $F_{(1,33)}=7.87, p=0.0084$, basal dendrite intersections: $F_{(1,33)}=0.00072, p=0.98$, apical dendrite length: ${ }^{*} F_{(1,33)}=4.79, p=0.036$, basal dendrite length: $F_{(1,33)}=0.0091, p=0.92 ;$ WT: $n=17$ cells from 5 mice; Foxp2 ${ }^{+/ R 552 H}: n=18$ cells from 4 mice. Data are represented as mean $\pm \mathrm{SEM} ;{ }^{*} p<0.05,{ }^{*} p<0.01$. n.s., not significant.

WT neurons for paired-pulse intervals of 50, 100, and $200 \mathrm{~ms}$ (two-way RM ANOVA, genotype effect, $F_{(1,36)}=0.00021$, $p=0.99$; WT: $n=20$ cells from three mice; Foxp $2^{+/ \mathrm{R} 552 \mathrm{H}}: n=18$ cells from 3 mice; Fig. 3C,D). Evoked PSCs and mEPSCs may be originating at different synapses, and may be controlled by divergent release mechanisms. Nevertheless, similar PPRs in WT and mutant mice suggest that release probability changes may be unlikely to fully account for the large mEPSC frequency decrease in Foxp $2^{+/ R 552 \mathrm{H}}$ neurons. mEPSC frequency decrease may at least in part reflect a reduction in synapse number arising from decreased dendritic length, or from reduced excitatory synapse density. We measured the density of dendritic spines in biocytin-filled primary and secondary dendrites of Foxp2+ neurons and found that it was comparable in WT and mutant neurons (WT: $n=36$ cells from 8 mice; Foxp $2^{+/ \mathrm{R} 552 \mathrm{H}}: n=21$ cells from 5 mice; primary, WT: $1.05 \pm 0.03$ spine $/ \mu \mathrm{m}$, Foxp $2^{+/ \mathrm{R} 552 \mathrm{H}}: 1.16 \pm 0.06$ spine $/ \mu \mathrm{m}$, Mann-Whitney test $p=0.17$; secondary, WT: $1.04 \pm 0.03$ spine/ $\mu \mathrm{m}$, Foxp $2^{+/ \mathrm{R} 552 \mathrm{H}}: 1.08 \pm 0.04$ spine/ $\mu \mathrm{m}$, Mann-Whitney test $p=0.44$; Fig. $3 E, F)$ Taken together, these results suggest that reduced dendritic length in Foxp $2^{+/ R 552 \mathrm{H}}$ neurons, rather than changes in spine density, contribute to decrease excitatory inputs.

Loss of Foxp2 function may also affect inhibitory synapses, as indicated by the increase in inhibitory currents in D1 receptorexpressing striatal neurons from mice with a heterozygous Foxp2 mutation (van Rhijn et al., 2018). Therefore, we recorded mIPSCs in WT and Foxp $2^{+/ R 552 \mathrm{H}}$ neurons of the auditory cortex to investigate GABAergic synapse properties. The frequency and amplitude of mIPSCs was similar in Foxp $2^{+/ R 552 H}$ and control neurons (WT: $n=12$ cells from three mice, Foxp2+/R552H cells: $n=14$ cells from four mice; frequency, WT: $0.90 \pm 0.10 \mathrm{~Hz}$, Foxp2 $2^{+/ \mathrm{R} 552 \mathrm{H}}: 0.93 \pm 0.14 \mathrm{pA}$, Mann-Whitney test, $p=0.66$; amplitude, WT: $17.8 \pm 4.9 \mathrm{pA}$, Foxp2 $2^{+/ \mathrm{R} 552 \mathrm{H}}: 19.2 \pm 5.2 \mathrm{pA}, t$ test, $p=0.47$; Fig. $3 G, H)$.

To assess intrinsic excitability in Foxp2+ neurons, we measured the firing frequency of APs in response to 500-ms 
depolarizing current steps from a membrane potential of $-70 \mathrm{mV}$, in the presence of APV, CNQX and GABAzine to block synaptic activity. We found that intrinsic excitability was significantly reduced in Foxp2 $2^{+/ R 552 H}$ neurons (WT: $n=34$ cells from 9 mice, Foxp $2^{+/ \mathrm{R} 552 \mathrm{H}}$ : $n=41$ cells from 9 mice; two-way $\mathrm{RM}$ ANOVA, genotype effect, $F_{(1,73)}=7.56$, $p=0.0075$; interaction, $F_{(25,1825)}=6.36$, $p<0.0001$; Fig. $4 A-C)$. The resting membrane potential (Vrest) was comparable in control and Foxp2 $2^{+/ \mathrm{R} 552 \mathrm{H}}$ neurons (WT: $-69.3 \pm 0.8 \mathrm{mV} ;$ Foxp $2^{+/ \mathrm{R} 552 \mathrm{H}}:-69.3$ $\pm 0.6 \mathrm{mV}$; $t$ test, $p=0.98$; Fig. $4 D)$. Neuronal capacitance was also similar (WT: $31.8 \pm 3.2$ pF; Fox p2 ${ }^{+/ R 552 H}: 36.1 \pm 2.9$ pF; Mann-Whitney test, $p=0.18$; Fig. $4 E$ ). The Rinput was increased in Foxp2 $2^{+/ R 552 \mathrm{H}}$ neurons (WT: $187 \pm 9 \mathrm{M} \Omega$; Foxp2 ${ }^{+/ \mathrm{R} 552 \mathrm{H}}$ : $223 \pm 12 \mathrm{M} \Omega$; Mann-Whitney test, $p=$ 0.013; Fig. 4F). We next studied separately the first AP of the spike train ("first AP") and all APs in the spike train except the first one ("non-first APs"). AP threshold was unchanged in Foxp2 $2^{+/ R 552 H}$ neurons (first AP, WT: $-45.1 \pm 0.9 \mathrm{mV}$, Foxp $2^{+/ \mathrm{R} 552 \mathrm{H}}$ : $-44.0 \pm 0.9 \mathrm{mV}$, Mann-Whitney test $p=$ 0.74; non-first APs, WT: $-40.3 \pm 0.8 \mathrm{mV}$, Foxp $2^{+/ \mathrm{R} 552 \mathrm{H}}:-40.5 \pm 0.8 \mathrm{mV}, t$ test $p=$ 0.89 ), but AP amplitude was decreased (first AP, WT: $90.1 \pm 1.5 \mathrm{mV}$, Foxp2 $2^{+/ R 552 \mathrm{H}}$ $84.9 \pm 1.7 \mathrm{mV}$, Mann-Whitney test $p=$ 0.024; non-first APs, WT: $80.2 \pm 1.3 \mathrm{mV}$, Foxp $2^{+/ \mathrm{R} 552 \mathrm{H}}: 74.7 \pm 1.4 \mathrm{mV}, t$ test $p=$ 0.005). AP half-width was slightly, but significantly, increased in Foxp2 $2^{+/ R 552 H}$ neurons for the non-first APs in the spike trains (first AP, WT: $0.92 \pm 0.02 \mathrm{~ms}$, Foxp $2^{+/ \mathrm{R} 552 \mathrm{H}}: 0.96 \pm 0.02 \mathrm{~ms}$, MannWhitney test $p=0.16$; non-first APs, WT: $\quad 1.34 \pm 0.05 \mathrm{mV}, \quad$ Foxp $2^{+/ R 552 \mathrm{H}}$ : $1.54 \pm 0.06 \mathrm{mV}$, Mann-Whitney test $p=0.012$; Fig. 4G,H). Spike frequency adaptation was comparable in WT and Foxp $2^{+/ R 552 H}$ neurons (WT: $n=34$ cells from 9 mice, Foxp $2^{+/ R 552 H}: n=38$ cells from 9 mice; two-way RM ANOVA, genotype effect, $F_{(1,70)}=0.028, p=0.87$; interaction, $F_{(9,630)}=0.22, p=0.99$; Fig. $\left.4 I\right)$. We hypothesized that the $\mathrm{R} 552 \mathrm{H}$ mutation may alter the expression of specific ion channels, and set out to identify the conductance(s) responsible for the decrease in neuronal excitability. Previous studies using chromatin immunoprecipitation coupled to microarray analysis (ChIP on chip) in heterologous cell lines and in cells from the developing human brain identified two ion channel subunit-encoding genes that are regulated by Foxp2, namely KCNB1 and KCND1 (Spiteri et al., 2007; Vernes et al., 2007). KCNB1 encodes $\mathrm{K}_{\mathrm{v}} 2.1$, a DR potassium channel subunit. KCND1 encodes
A

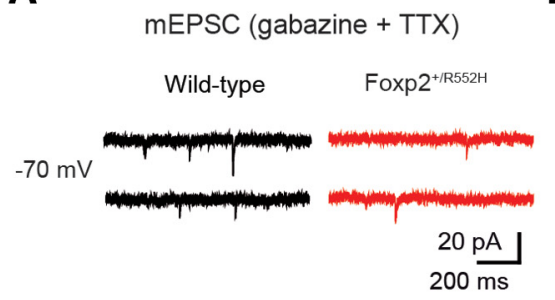

C

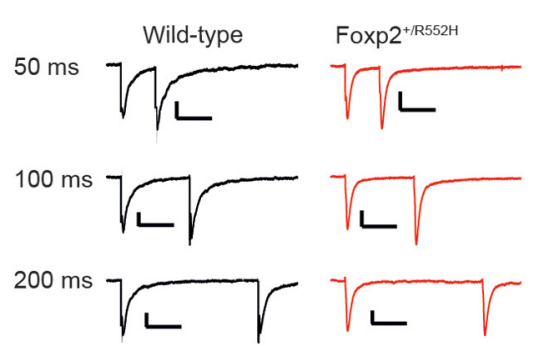

E

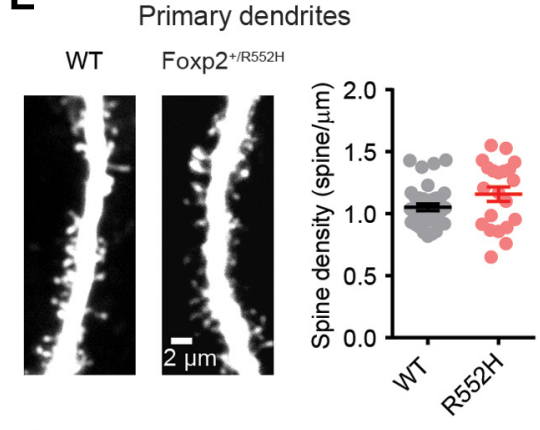

G

$\operatorname{mIPSC}(C N Q X+A P V+T T X)$

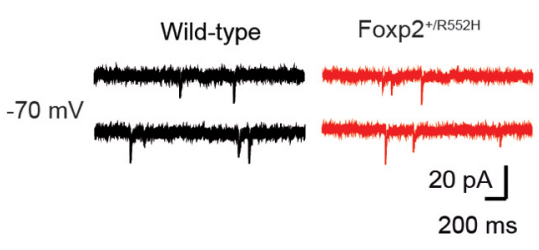

B
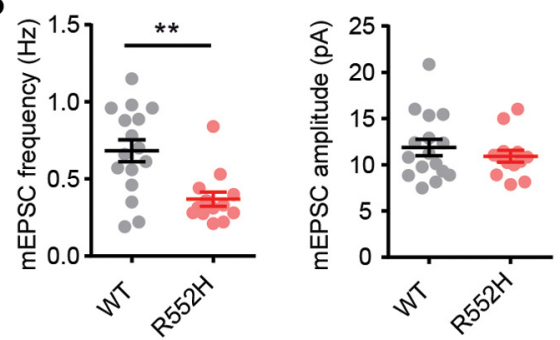

D

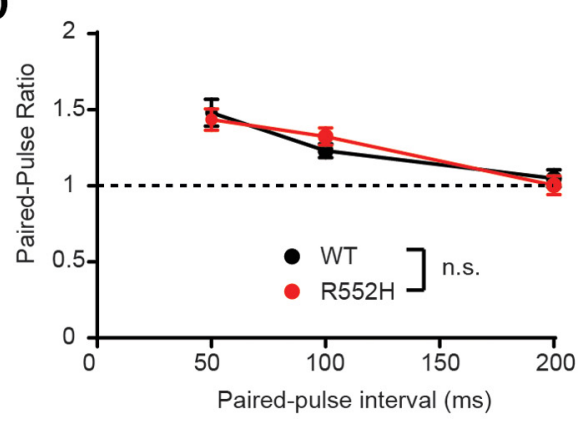

$\mathbf{F}$

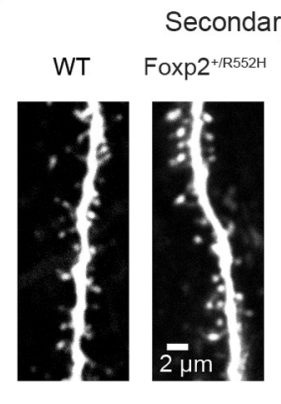

H

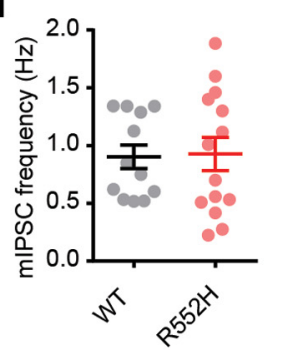

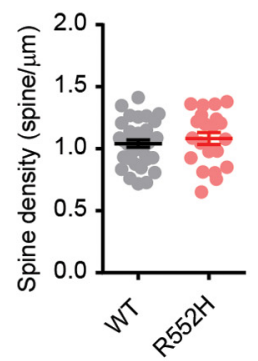

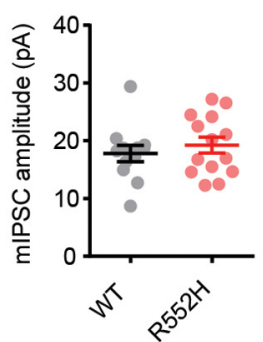

Figure 3. Decrease in excitatory, but not inhibitory synaptic transmission in Foxp2 ${ }^{+/ R 552 H}$ cortical neurons. $A$, Sample traces of mEPSCS from WT and Foxp2 ${ }^{+/ R 552 H}$ cells recorded at $-70 \mathrm{mV}$ in the presence of TTX and GABAzine. $B$, Mean

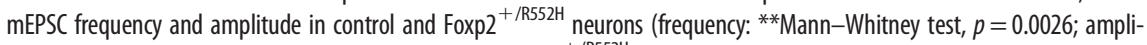
tude: $t$ test, $p=0.42$, WT: $n=16$ cells from 4 mice; Foxp2 ${ }^{+/ R 552 H}: n=13$ cells from 3 mice). C, Average traces of EPSCs evoked by paired-pulse stimulation with 50-, 100-, and 200-ms interpulse intervals, recorded from a control neuron (left traces) and a Foxp2 ${ }^{+/ R 552 H}$ neuron (right traces). D, Unchanged PPR for interpulse intervals of 50, 100, and $200 \mathrm{~ms}$, indicating an absence of presynaptic release alterations in Foxp2 ${ }^{+/ R 552 \mathrm{H}}$ neurons. WT: $n=20$ cells from 3 mice; Foxp2 ${ }^{+/ R 552 \mathrm{H}}: n=18$ cells from 3 mice; two-way RM ANOVA, genotype effect, $F_{(1,36)}=0.00021, p=0.99$. n.s., not significant. $E$, Maximal intensity projections of $3 \mathrm{D}$ confocal stacks showing spines in primary apical dendrites from a WT and a Foxp2 ${ }^{+/ R 552 \mathrm{H}}$ neuron (left), and spine density histogram (right; WT: $n=36$ cells from 8 mice; Foxp2 ${ }^{+/ R 552 H}: n=21$ cells from 5 mice). $\boldsymbol{F}$, Same as in $\boldsymbol{E}$, for secondary apical dendrites. G, Example traces of mIPSCs from each genotype recorded at $-70 \mathrm{mV}$ in the presence of TTX, APV and CNQX using a high chloride intracellular solution. $\boldsymbol{H}$, Mean mIPSC frequency and amplitude in WT ( $n=12$ cells from 3 mice) and Foxp2 ${ }^{+/ R 552 H}$ cells ( $n=14$ cells from 4 mice); frequency: Mann-Whitney test, $p=0.66$, amplitude: $t$ test, $p=0.47$. Throughout, data are represented as mean \pm SEM.

$\mathrm{K}_{\mathrm{v}} 4.1$, an A-type potassium channel subunit. We hypothesized that increased $\mathrm{K}_{\mathrm{v}} 2.1$ and/or $\mathrm{K}_{\mathrm{v}} 4.1$ expression may contribute to decreased excitability in Foxp $2^{+/ R 552 H}$ neurons. We measured DR and A-type potassium currents using the whole-cell configuration. We found that DR 
A
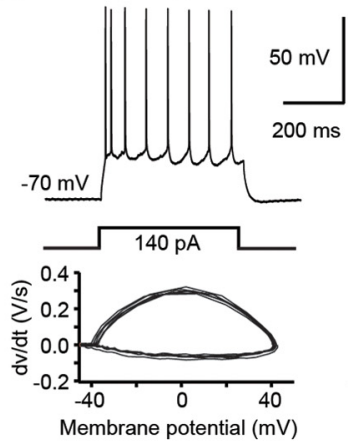

C
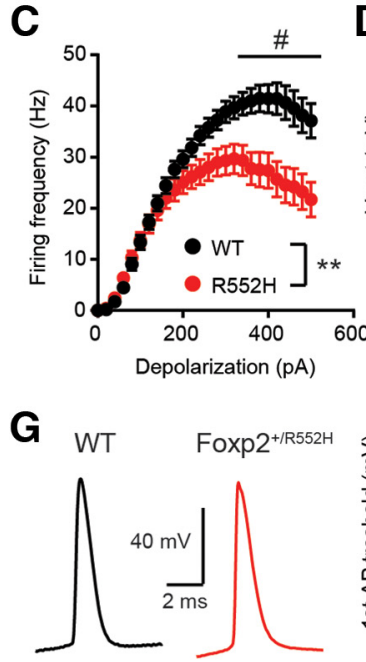

H

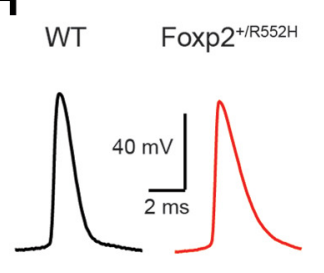

Foxp2 $2^{+/ R 552 H}$
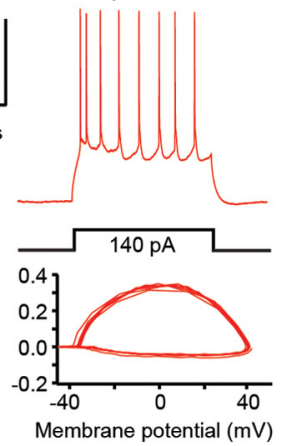

D
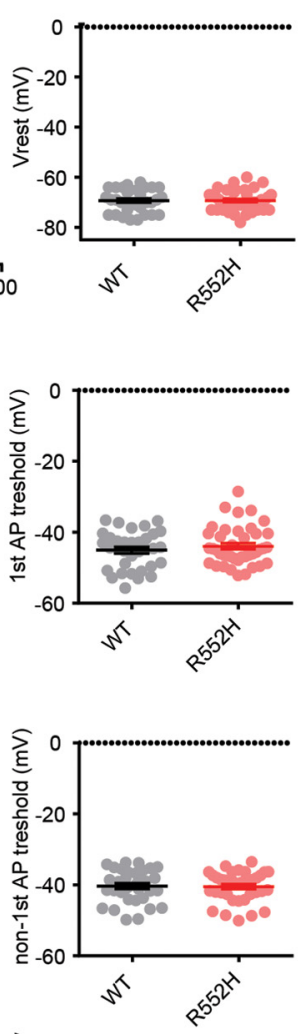

I

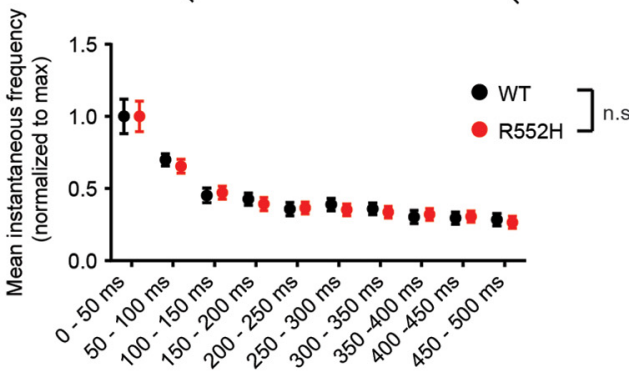

B
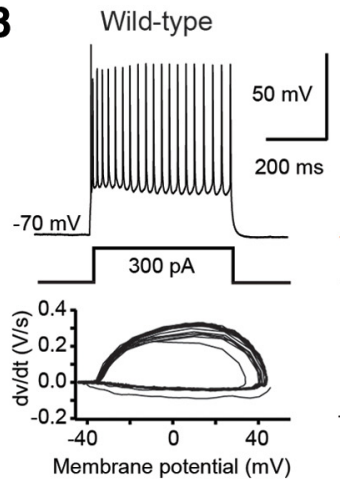

E

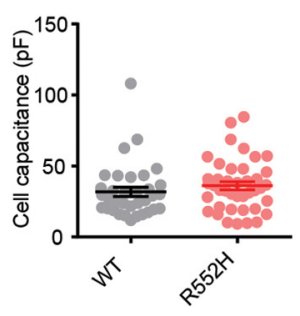

$\mathbf{F}$
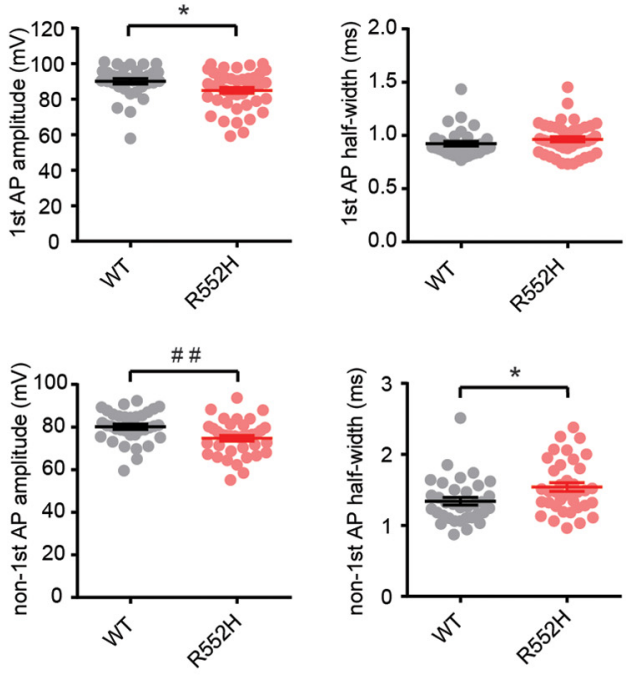

Foxp2 $2^{+/ R 552 H}$
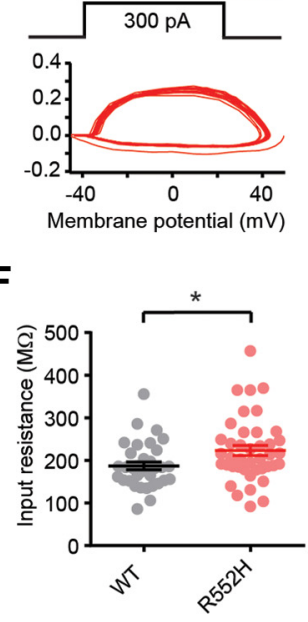

\section{s.}

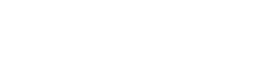


results indicate that neither $\mathrm{K}_{\mathrm{v}} 2.1$ nor $\mathrm{K}_{\mathrm{v}} 4.1$ expression is affected by the loss of function of Foxp2 in Layer VI Foxp2 $2^{+/ R 552 H}$ neurons.

We then set out to investigate potassium conductances that are not direct transcriptional targets of Foxp2. In the aforementioned ChIP on chip experiments, FOXP2 was also shown to regulate the expression of $G A B B R 1$, a gene coding for the $\beta 1$ subunit of $\mathrm{GABA}_{\mathrm{B}}$ receptors (Spiteri et al., 2007; Vernes et al., 2007). $\mathrm{GABA}_{\mathrm{B}}$ receptors are metabotropic GABA receptors that are linked via $\mathrm{G}$-proteins to potassium channels of the G-protein-gated inwardly rectifying (GIRK) family. GIRK channels hyperpolarize neurons in response to the activation of G-protein-coupled receptors and thus control the excitability of neurons through GIRK-mediated inhibition (Lüscher and Slesinger, 2010). We surmised that Foxp2-dependent $\mathrm{GABA}_{\mathrm{B}} / \mathrm{GIRK}$ channel activity may contribute to decrease neuronal excitability in Foxp $2^{+/ R 552 H}$ neurons. We first sought to confirm that potassium conductances are responsible for the decrease in neuronal excitability in Foxp $2^{+/ R 552 H}$ mice. We reasoned that if GIRK channels are involved, lowering the extracellular potassium concentration should increase the driving force for potassium and amplify the effect of the R552H mutation on neuronal excitability at lower depolarizing currents, where the equilibrium potential for potassium $(-95.7 \mathrm{mV})$ is close to the membrane potential. Indeed, on changing the extracellular concentration from 3.5 to $1.5 \mathrm{~mm}$, which in our experimental conditions decreased the equilibrium potential for potassium from -95.7 to $-117.9 \mathrm{mV}$, we noticed that the difference in firing frequency between control and mutant neurons became significant for lower depolarizing currents (WT: $n=18$ cells from three mice, Foxp $2^{+/ \mathrm{R} 552 \mathrm{H}}: n=22$ cells from three mice; two-way RM ANOVA, genotype effect, $F_{(1,38)}=10.50, p=0.0025$; Sidak's post hoc test: $p<0.05$ at $100 \mathrm{pA}$ for $\left[\mathrm{K}^{+}\right]=1.5 \mathrm{~mm}$ instead of $340 \mathrm{pA}$ for $\left[\mathrm{K}^{+}\right]=3.5 \mathrm{~mm}$, Fig. $6 A, B$, compare with Fig. $4 C$ ). These results supported the hypothesis that voltage-independent potassium channels are upregulated in Foxp $2^{+/ \mathrm{R} 552 \mathrm{H}}$ mice.

To assess $\mathrm{GABA}_{\mathrm{B}} / \mathrm{GIRK}$ signaling, we first examined whether Foxp2+ neurons in the auditory cortex express $\mathrm{GABA}_{\mathrm{B}}$ receptors. In six voltage-clamped Foxp $2+$ neurons from four control mice, bath application of the $\mathrm{GABA}_{\mathrm{B}}$ agonist baclofen $(30 \mu \mathrm{M})$ evoked an outward current $\left(I_{\text {Baclofen }}\right)$ readily reversed by the specific antagonist CGP $54626(10 \mu \mathrm{M})$, in line with a previous study demonstrating $\mathrm{GABA}_{\mathrm{B}}$ receptor expression in cortical Layer V-VI pyramidal cells (Hearing et al., 2013; Fig. 7A). $I_{\text {Baclofen }}$ was also abolished in the presence of the GIRK blocker barium $\left(\mathrm{Ba}^{2+} ; 100 \mu \mathrm{M} ; n=9\right.$ cells from 5 mice; Fig. $\left.7 B\right)$. In the presence of baclofen $(30 \mu \mathrm{M})$, intrinsic excitability was strongly decreased in WT mice, indicating that activation of $\mathrm{GABA}_{\mathrm{B}}-\mathrm{R}$ recapitulates the effect of the Foxp2 mutation on neuronal excitability (control: $n=34$ cells from 9 mice, baclofen: $n=15$ cells from three mice; two-way RM ANOVA, genotype effect, $F_{(1,47)}=$ 11.1, $p=0.0017$; interaction, $F_{(25,1175)}=2.847 ; p<0.0001$; Fig. $7 C, D)$. We then investigated whether the Foxp2 mutation
B

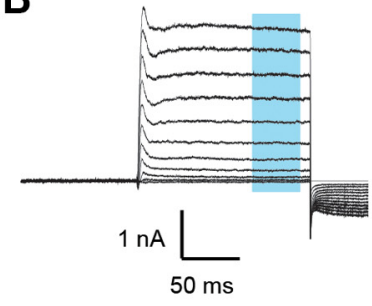

E

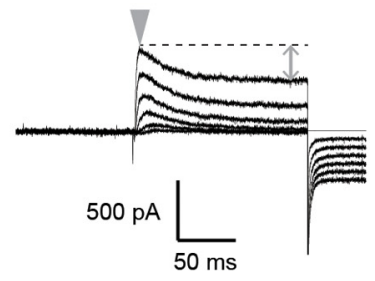

$\mathbf{F}$
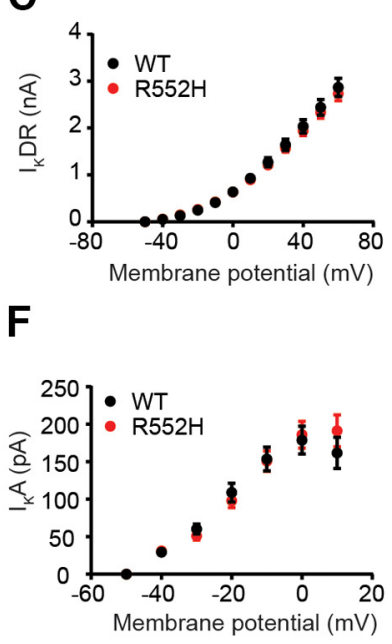

Figure 5. Unchanged DR and A-type potassium currents, two putative transcriptional targets of Foxp2, in Foxp2 $2^{+/ R 552 H}$ neurons. A, Activation protocol for DR potassium channels. Following a 400 -ms prepulse to $-120 \mathrm{mV}$, the membrane potential was stepped to a test potential ranging from -50 to $+60 \mathrm{mV}$ in 10-mV increments, in the presence of synaptic

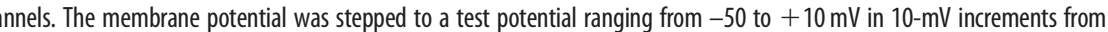
head) minus the residual DR current (double arrow). $\boldsymbol{F}, I_{A}$ after leak current subtraction in WT ( $n=21$ cells from 3 mice) and Foxp2 ${ }^{+/ R 552 H}$ neurons ( $n=20$ cells from 3 mice); two-way RM ANOVA, genotype effect, $F_{(1,39)}=0.028, p=0.87$.

changed $I_{\text {Baclofen }}$. We found that $I_{\text {Baclofen }}$ was significantly higher in Foxp $2^{+/ R 552 \mathrm{H}}$ neurons, consistent with increased $\mathrm{GABA}_{\mathrm{B}}$ receptor signaling in Foxp2 mutant neurons with diminished Foxp2 transcriptional activity (WT: $n=27$ cells from 12 mice, Foxp2 ${ }^{+/ \mathrm{R} 552 \mathrm{H}}: n=16$ cells from 7 mice; Mann-Whitney test, $p=0.020$; Fig. $7 E, F)$.

We then tested the hypothesis that GIRK channel activity is upregulated as a consequence of increased $\mathrm{GABA}_{\mathrm{B}}$ receptor signaling in Foxp $2^{+/ R 552 H}$ neurons. In line with this hypothesis, inward-rectifying potassium currents were larger in Foxp $2^{+/ R 552 H}$ neurons than in control neurons (WT: $n=25$ cells from four mice, Foxp2 ${ }^{+/ \mathrm{R} 552 \mathrm{H}}: n=20$ cells from four mice; two-way RM ANOVA, genotype effect, $F_{(1,43)}=4.27, p=0.045$; Fig. $\left.8 A-C\right)$. $\mathrm{Ba}^{2+}(100 \mu \mathrm{M})$ linearized the $\mathrm{i}-\mathrm{v}$ curve of potassium currents, confirming that inward-rectifying potassium channels were blocked (Fig. $8 D$ ). In the presence of $\mathrm{Ba}^{2+}$, the Rinput increased sharply both in Foxp2 $2^{+/ R 552 H}$ and in control neurons (Fig. $8 E$, compare with Fig. $4 F$ ). However, the increase in Rinput was more pronounced in Foxp $2^{+/ R 552 H}$ neurons than in control neurons, resulting in a $24.6 \%$ higher mean Rinput in mutant neurons than in WT neurons in the presence of $\mathrm{Ba}^{2+}$ (WT: $n=20$ cells from four mice; Foxp $2^{+/ \mathrm{R} 552 \mathrm{H}}: n=25$ cells from three mice; Mann-Whitney test, $p=0.0037)$. Thus, elevated GIRK channel activity in Foxp $2^{+/ R 552 H}$ neurons decreases membrane resistance. Indeed $\mathrm{i}-\mathrm{v}$ curves in Foxp $2^{+/ R 552 \mathrm{H}}$ and control neurons in the presence of $\mathrm{Ba}^{2+}$ became comparable after normalizing for differences in Rinput (two-way RM ANOVA, genotype effect, $F_{(1,43)}=$ $1.84, p=0.18$; Fig. $8 F$ ).

Finally, we tested whether elevated $\mathrm{GABA}_{\mathrm{B}} / \mathrm{GIRK}$ signaling is responsible for the decreased excitability of Foxp $2^{+/ \mathrm{R} 552 \mathrm{H}}$ neurons. In the presence of $\mathrm{Ba}^{2+}$, the difference in intrinsic excitability between Foxp $2^{+/ R 552 H}$ neurons and control neurons was strongly 
A
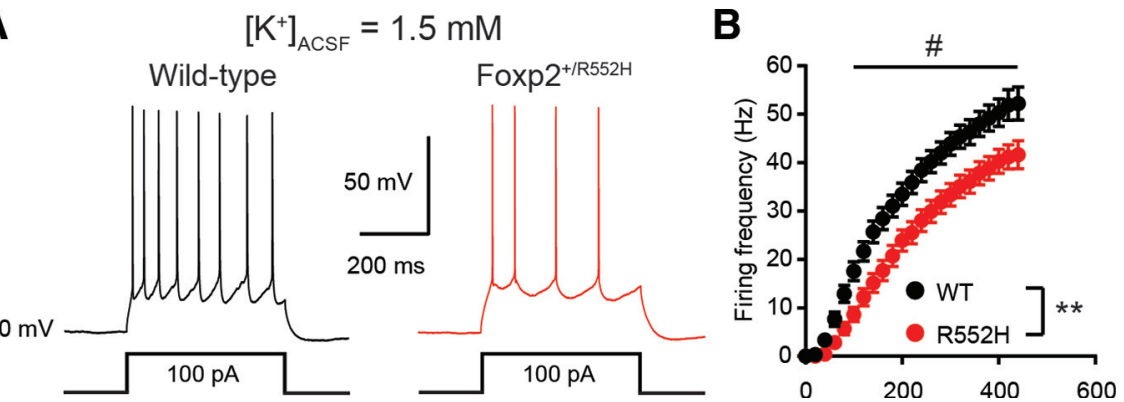

Figure 6. Enhanced effect of the $\mathrm{R} 552 \mathrm{H}$ mutation on the firing response to small depolarizing currents by decreasing extracellular potassium concentration. $\boldsymbol{A}$, Example spike trains evoked by somatic current injections in a WT (black traces) and a Foxp2 ${ }^{+/ R 552 \mathrm{H}}$ neuron (red traces) for $\left[\mathrm{K}^{+}\right]_{\text {ACSF }}=1.5 \mathrm{~mm}$ instead of $\left[\mathrm{K}^{+}\right]_{\mathrm{ACSF}}=3.5 \mathrm{~mm}$ which shifts the equilibrium potential for potassium from -95.7 to $-117.9 \mathrm{mV}$. Note that in this condition Foxp2 $2^{+/ R 552 \mathrm{H}}$ neurons already fire fewer APs than control WT neurons in response to small $(100 \mathrm{pA})$ depolarizations. $\boldsymbol{B}$, fi curve (mean \pm SEM) for control $(n=18$ cells from 3 mice) and Foxp2 ${ }^{+/ R 552 H}$ neurons ( $n=22$ cells from 3 mice) in 1.5 mm potassium conditions; **two-way RM ANOVA, genotype effect, $F_{(1,38)}=10.50, p=0.0025 ; \# p<0.05$, Sidak's post hoc test. The firing frequency of control and Foxp2 ${ }^{+/ R 552 H}$ neurons differed in response to lower depolarizing current injections than in the $\left[\mathrm{K}^{+}\right]_{\mathrm{ACSF}}=3.5 \mathrm{~mm}$ condition (Fig. $4 B$ ), consistent with the implication of voltage-independent potassium channels.

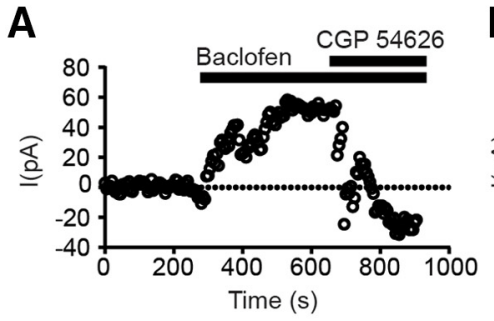

C

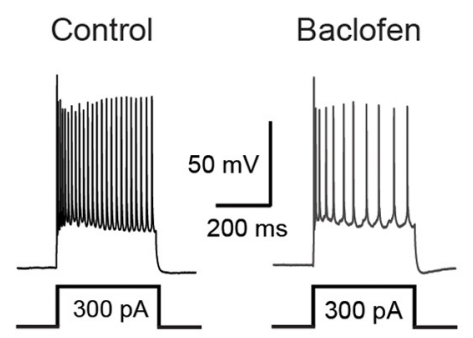

E

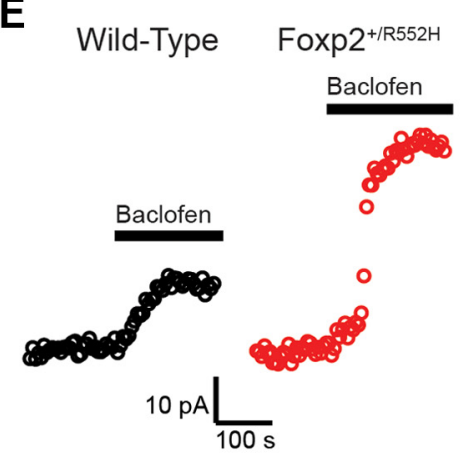

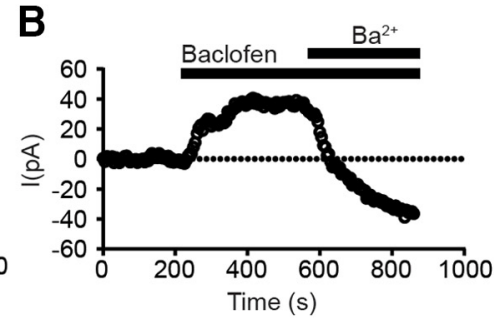

D

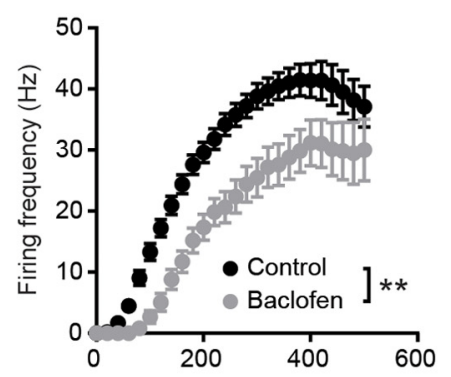

$\mathbf{F}$

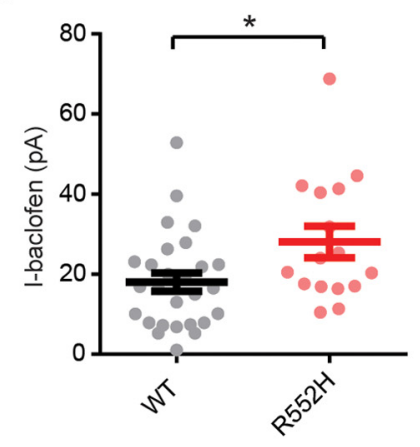

Figure 7. Increased $\mathrm{GABA}_{\mathrm{B}}$-mediated currents in Foxp2 ${ }^{+/ \mathrm{R} 552 \mathrm{H}}$ cortical neurons. $\boldsymbol{A}$, Representative current activated by $30 \mu \mathrm{M}$

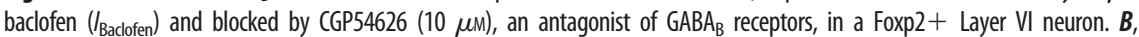
Example trace showing that $I_{\text {Baclofen }}$ is inhibited by barium $(100 \mu \mathrm{m})$, a blocker of GIRK channels, in a Foxp2 + Layer VI neuron. C, Sample spike trains evoked by a 300-pA somatic current injection in the absence (left) or presence of baclofen (right). D, f-i curve (mean \pm SEM) for Foxp2+ neurons in the absence ( $n=34$ cells from 9 mice, same recordings as WT in Fig. 4C) or presence of baclofen ( $n=15$ cells from 3 mice), showing that baclofen recapitulates the effect of the R552H mutation on intrinsic excitability; ${ }^{* *}$ two-way RM ANOVA, genotype effect, $F_{(1,47)}=11.1, p=0.0017$. $\boldsymbol{E}$, Representative recordings of $I_{\text {Badlofen }}$ in a WT control and in a Foxp2 ${ }^{+/ R 552 H}$ neuron. $\boldsymbol{F}, I_{\text {Baclofen in WT }(~}=27$ cells from 12 mice) and Foxp2 ${ }^{+/ R 552 H}$ neurons $(n=16$ cells from 7 mice); * Mann-Whitney test, $p=0.020$; bars represent the mean $\pm \mathrm{SEM}$; full circles show individual recordings. attenuated (WT: $n=17$ cells from three mice, Foxp2 $2^{+/ \mathrm{R} 552 \mathrm{H}}: n=16$ cells from three mice; two-way RM ANOVA, genotype effect, $F_{(1,31)}=0.81, p=0.37$; interaction $F_{(25,775)}=1.653, p=0.023$; Fig. $\left.9 A, B\right)$. Since $\mathrm{Ba}^{2+}$ is not selective for GIRK channels, we also assessed intrinsic excitability in the presence of Tertiapin Q (100 nm), a selective blocker of GIRK channels. In the presence of Tertiapin Q, the effect of the $\mathrm{R} 552 \mathrm{H}$ mutation on excitability was also strongly attenuated (WT: $n=22$ cells from three mice, Foxp2 $2^{+/ \mathrm{R} 552 \mathrm{H}}: n=28$ cells from 6 mice; two-way RM ANOVA, genotype effect, $F_{(1,48)}=0.0003, p=0.99$; interaction, $F_{(25,1200)}=2.727, p<0.0001$; Fig. $\left.9 C, D\right)$, further substantiating the role of GIRK signaling in the lower intrinsic excitability of Foxp $2^{+/ R 552 H}$ neurons. GIRK channel may show constitutive activity even in the absence of $\mathrm{GABA}_{\mathrm{B}}$ signaling (Peleg et al., 2002; Luján et al., 2009). Thus GIRK-dependent changes in neuronal excitability could reflect alterations in $\mathrm{GABA}_{\mathrm{B}}$ signaling or, alternatively, in constitutive GIRK activation. To distinguish between these two possibilities, intrinsic excitability was investigated using CGP $55845(10 \mu \mathrm{M})$ to block $\mathrm{GABA}_{\mathrm{B}}$ receptors. F-i curves in WT and Foxp2 $2^{+/ R 552 H}$ neurons did not differ in the presence of CGP 55845 (WT: $n=23$ cells from four mice, Foxp $2^{+/ \mathrm{R} 552 \mathrm{H}}: n=26$ cells from three mice; two-way RM ANOVA, genotype effect, $F_{(1,46)}=0.0008, p=0.98$; interaction, $F_{(25,1150)}=0.77 ; p=0.78$; Fig. $\left.9 E, F\right)$, suggesting that elevated basal $\mathrm{GABA}_{\mathrm{B}}$ activity mediates, at least in part, the GIRK-dependent decrease in neuronal excitability. However, it should be noted that CGP 55845 , while being a competitive antagonist of $\mathrm{GABA}_{\mathrm{B}}$ receptors (Waldmeier et al., 1994), was also shown to act as an inverse agonist, i.e., to attenuate constitutive (ligand-independent) G-protein signaling (Mukherjee et al., 2006; Gonzalez et al., 2018). Therefore, it remains possible that constitutive GIRK activation contributes to decrease intrinsic excitability in Foxp $2^{+/ R 552 H}$ neurons.

\section{Discussion}

In this study, we show that the arginine to histidine substitution in Foxp2 found in affected members of the KE family alters neuronal morphology and function in auditory cortex. We report three major neuronal deficits in heterozygous mutants. First, mutant Foxp2+ neurons have shorter and less complex apical dendrites. Second, the excitatory input is disrupted in mutant neurons, as shown by the decrease in the frequency of spontaneous excitatory synaptic events, while the inhibitory input is not 
affected. Third, mutant neurons are less excitable, which is largely the consequence of an increase in $\mathrm{GABA}_{\mathrm{B}} / \mathrm{GIRK}$ signaling. While decreased neurite length and excitatory synapse number were previously shown to be controlled by Foxp2 in striatal neurons, this is the first demonstration of Foxp2-dependent $\mathrm{GABA}_{\mathrm{B}}$ and GIRK activation. The etiologic $\mathrm{R} 552 \mathrm{H}$ mutation results in both decreased excitatory synaptic input and decreased neuronal gain through $\mathrm{GABA}_{\mathrm{B}} / \mathrm{GIRK}$ overactivation, reflecting a loss of homeostasis in Foxp2+ cortical neurons.

\section{Reduced dendrite length}

We observed a significant reduction in the length and complexity of apical dendrites in Foxp $2^{+/ R 552 H}$ neurons of the auditory cortex. Reduced neurite growth was also found in striatal medium spiny neurons of mutant mice carrying one nonfunctional Foxp2 allele. Conversely, medium spiny neurons show increased dendrite length in mice with a humanized, "gain-of-function” Foxp2 gene (Enard et al., 2009). The humanized Foxp2 also increases dendrite length in Layer VI neurons of the motor cortex and neurons in the thalamus (Reimers-Kipping et al., 2011). An unbiased genomic screen in mouse embryos identified Foxp2-dependent gene networks involved in neurite outgrowth in the developing brain (Vernes et al., 2011). Thus, Foxp2-dependent gene expression during early development shapes mature neuronal morphology and hence connectivity. Several direct transcriptional targets of the Foxp2 protein have been associated with neurite growth. For example, the Neuritin-encoding Nrn1 gene promotes neuritogenesis under the control of neural activity and neurotrophins (Naeve et al., 1997). Other putative mediators of Foxp2 effects on neuronal morphology include Efnb2 (Ephrin-b2), and Pak3, a downstream effector of the Rho family of GTPases, both of which play critical roles in neurite growth (Yue et al., 1999; Huang et al., 2011; Vernes et al., 2011). Therefore, the effect of the $\mathrm{R} 552 \mathrm{H}$ mutation on neuronal morphology is likely to result from the loss of Foxp2-mediated transcriptional control at multiple loci in the genome of developing neurons, although indirect, activity-dependent morphologic changes cannot be ruled out.

\section{Selective loss of excitatory inputs}

In the developing striatum, Foxp 2 promotes excitatory synapse formation by negatively regulating myocyte enhancer factor $2 \mathrm{C}$ (MEF2C; Chen et al., 2016), a gene associated with severe mental retardation and cerebral malformations (Le Meur et al., 2010). ChIP coupled to qPCR (ChIP-qPCR) showed direct binding of Foxp2 to the second intron of the MEF2C gene (Chen et al., 2016). In contrast, other results suggested that Foxp2 opposes synapse formation. Thus, Foxp2 was shown to directly repress the expression of SRPX2, a language-associated gene that promotes synapse formation in cortical neurons (Sia et al., 2013). Cultured neocortical neurons transfected with FoxP2 have a decreased density of excitatory synaptic markers and spines,
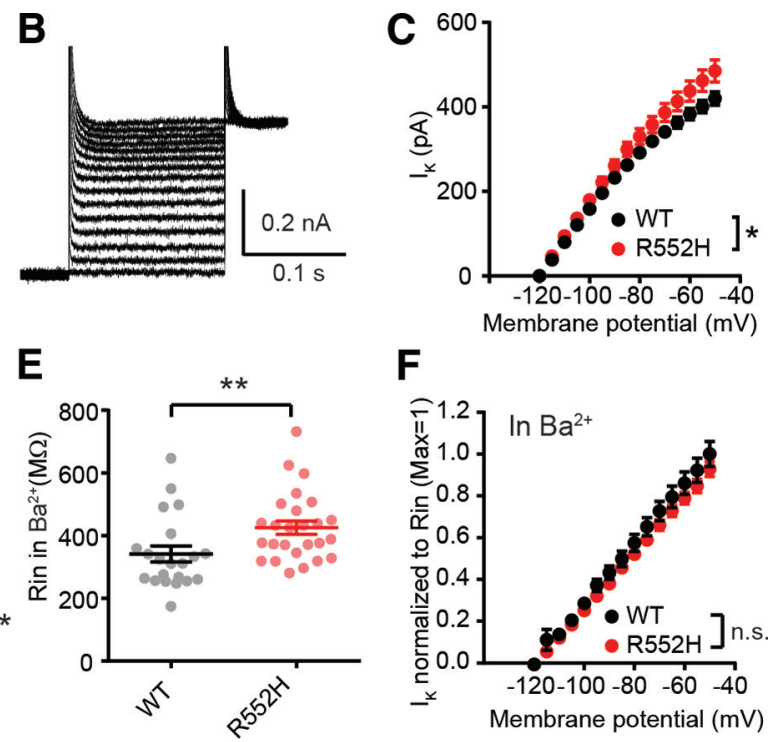

Figure 8. Increased Barium-sensitive potassium currents in Foxp2 $2^{+/ R 552 H}$ neurons. A, Activation protocol for voltage-independent potassium channels. Following a prepulse to $-120 \mathrm{mV}$, the membrane potential was stepped to a test potential neurons ( $n=25$ cells from 3 mice) in the presence of barium $(100 \mu \mathrm{m}) ;{ }^{* *}$ two-way RM ANOVA, genotype rons than in control WT neurons, in contrast to currents shown in $\boldsymbol{C}$. $\boldsymbol{E}$, Rinput in WT and Foxp2 ${ }^{+/ R 552 \mathrm{H}}$ neurons (same

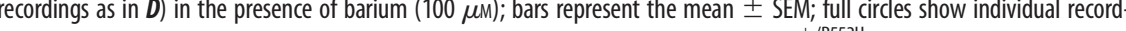
type effect, $F_{(1,43)}=1.84, p=0.18$. n.s., not significant.

which is rescued by the co-transfection of Foxp2 and SRPX2. In addition, expression of a mutant Foxp 2 protein with the $\mathrm{R} 552 \mathrm{H}$ mutation does not change synaptic density, demonstrating that the transcriptional activity of Foxp2 is necessary for its effect on synaptic density (Sia et al., 2013). Here, we did not find evidence for a change in spine density in Foxp $2^{+/ R 552 H}$ neurons from the auditory cortex. The selective decrease in functional excitatory input to Foxp $2^{+/ R 552 H}$ neurons may be at least partly caused by a reduction in dendritic length that primarily affects distal dendrites. Indeed, glutamatergic synapses form preferentially on the distal dendritic arborizations of pyramidal cells. In contrast, GABAergic synapses tend to be more numerous on proximal dendritic regions (Megías et al., 2001; García-López et al., 2006). Therefore, the shortening of apical dendrites in Foxp2 mutant neurons may disproportionally affect distal excitatory synapses, while preserving more proximal GABAergic synapses.

Increased GABAB/GIRK signaling in Foxp $2^{+/ R 552 H}$ neurons Increased $\mathrm{GABA}_{\mathrm{B}} / \mathrm{GIRK}$ signaling in Foxp2 mutant neurons decreases intrinsic neuronal excitability through elevated GIRK activity. GIRK channels are activated by binding of the G-protein subunits $\mathrm{G} \beta \gamma$ to their intracellular domains following the activation of $\mathrm{GABA}_{\mathrm{B}}$ receptors, but they have also been shown to possess constitutive activity even in the absence of $\mathrm{GABA}_{\mathrm{B}}$ signaling, because of direct binding of the $\mathrm{G} \alpha$ subunit (Peleg et al., 2002; Luján et al., 2009). In cortical Foxp $2^{+/ R 552 H}$ neurons, higher GIRK channel activity seems to results primarily from increased $\mathrm{GABA}_{\mathrm{B}}$ signaling, since the GIRK-dependent hypoexcitability of Foxp $2^{+/ R 552 \mathrm{H}}$ neurons is normalized by CGP55845, a $\mathrm{GABA}_{\mathrm{B}} \mathrm{R}$ antagonist. Heightened $\mathrm{GABA}_{\mathrm{B}} / \mathrm{GIRK}$ signaling in Foxp $2^{+/ R 552 H}$ mutant mice has also other implications for 
A
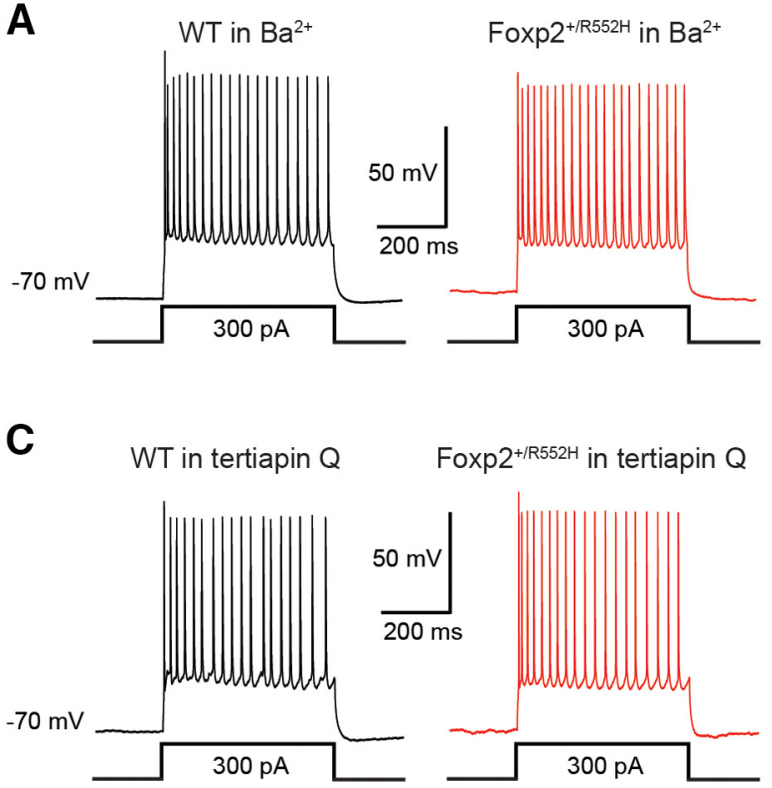

$\mathbf{E}$

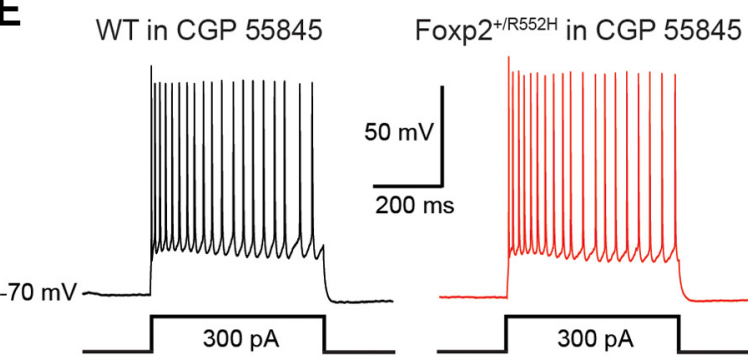

B

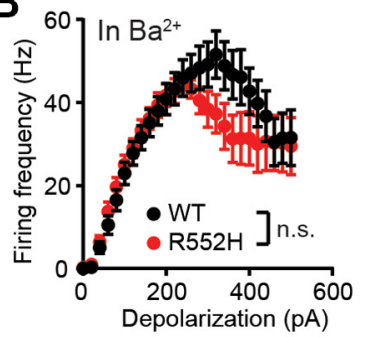

D

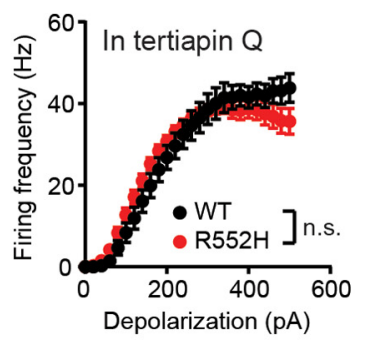

$\mathbf{F}$

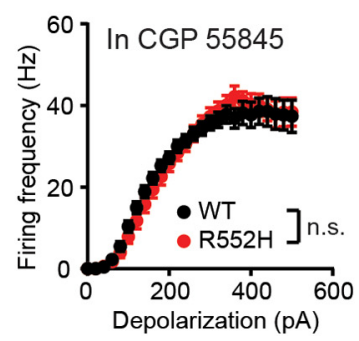

Figure 9. $G A B A_{B}$ - and GIRK-dependent effect of the R552H mutation on intrinsic neuronal excitability. $\boldsymbol{A}$, Sample spike trains evoked by a 300-pA somatic current injection in a WT (left) and a Foxp2 ${ }^{+/ R 552 H}$ neuron (right) in the presence of barium $\left(100 \mu \mathrm{M}\right.$ ). $\boldsymbol{B}$, Mean f-i curve ( \pm SEM) for WT ( $n=17$ cells from 3 mice) and Foxp2 ${ }^{+/ R 552 H}$ neurons ( $n=16$ cells from 3 mice) in the presence of barium; two-way RM ANOVA, genotype effect, $F_{(1,31)}=0.81, p=0.37$. C, Sample spike trains evoked by a 300-pA somatic current injection in a WT (left) and a Foxp2 ${ }^{+/ R 552 \mathrm{H}}$ neuron (right) in the presence of Tertiapine $Q(100$ nM) to selectively block GIRK channels. $D$, Mean f-i curve ( \pm SEM) for WT ( $n=22$ cells from 3 mice) and Foxp2 $2^{+/ R 552 H}$ neurons ( $n=28$ cells from 6 mice) in the presence of barium; two-way RM ANOVA, genotype effect, $F_{(1,48)}=0.0003, p=0.99$. $\boldsymbol{E}$, Sample spike trains evoked by a 300-pA somatic current injection in a WT (left) and a Foxp2 ${ }^{+/ 2552 \mathrm{H}}$ neuron (right) in the presence of CGP $55845(10 \mu \mathrm{m})$ to block GABA ${ }_{B}$ receptors. $\boldsymbol{F}$, Mean f-i curve ( \pm SEM) for WT ( $n=23$ cells from 4 mice) and Foxp2 ${ }^{+/ R 552 H}$ neurons ( $n=26$ cells from 3 mice) in the presence of (GP 55 845; two-way RM ANOVA, genotype effect, $F_{(1,46)}$ $=0.0008, p=0.98$. n.s., not significant.

cortical neurotransmission. It has been proposed that $\mathrm{GABA}_{\mathrm{B}}$ receptors/GIRK channels complexes may be located in the vicinity of postsynaptic $\mathrm{GABA}_{\mathrm{A}}$ receptors or in a neighboring dendritic spine (Lüscher and Slesinger, 2010). Strong or repetitive stimulation of GABAergic axons, for example in conditions of rhythmic activity, activates $\mathrm{GABA}_{\mathrm{B}}$ receptors through GABA spillover from nearby inhibitory synapses and mediates a slow, GIRK-mediated synaptic current (Scanziani, 2000). This suggests that Foxp2 $2^{+/ R 552 H}$ neurons may receive increased inhibitory inputs in conditions of elevated network activity.

\section{Relationship between GIRK activation and decreased} intrinsic excitability

Rinput (measured at $-65 \mathrm{mV}$ ) was increased in Foxp $2^{+/ R 552 H}$ neurons (Fig. $4 F$ ), possibly as a consequence of decreased dendrite length, and/or altered expression of yet unidentified transcriptional targets of Foxp2. However, the effects of an increase in Rinput (measured at $-65 \mathrm{mV}$ ), which is expected to promote neuronal excitability, may be counterbalanced at depolarized potentials by the increase in GIRK channel activity in Foxp $2^{+/ R 552 H}$ neurons. Thus, elevated GIRK channel activation at depolarized potentials not only promotes membrane hyperpolarization in Foxp $2^{+/ R 552 H}$ neurons, thereby opposing AP firing, but also shifts the change in Rinput observed near Vrest to the opposite direction: indeed, inward rectifying potassium channel activity in Foxp $2^{+/ R 552 H}$ neurons decreases Rinput at depolarized membrane potentials (see the difference between Fig. $8 C$ and $D$ ). In summary, the most parsimonious explanation for the decreased excitability of Foxp2 $2^{+/ R 552 H}$ neurons is that despite a moderate increase in Rinput at Vrest, Foxp2 $2^{+/ R 552 H}$ neurons show reduced excitability at depolarized potentials because of an excess of GIRK-mediated currents which may prevent AP firing through (1) membrane hyperpolarization and (2) decreased Rinput ("shunting inhibition”). Intriguingly, increased GIRK channel activity did not modify Vrest in Foxp2 ${ }^{+/ R 552 H}$ neurons, possibly owing to the low driving force for potassium at potentials that are close to Vrest in our experimental conditions, and/or to homeostatic compensatory mechanisms.

\section{Loss of homeostasis}

The identification of genomic variants associated with neurodevelopmental syndromes is rapidly advancing. It has been proposed that disease-associated variants converge on common molecular networks mediating distinct endophenotypes, such as speech and language, across clinically distinct syndromes. Disrupted neuronal homeostasis may precipitate at the network level leading to common clinical endpoints (Ramocki and Zoghbi, 2008). Here, we show that the R552H mutation disrupts the homeostatic adaptation of neuronal excitability to alterations in synaptic inputs. Homeostatic mechanisms allow neural networks to maintain stability of activity in the face of changing inputs. For instance, blocking excitatory synaptic activity results in a homeostatic decrease in neuronal intrinsic excitability (Desai et al., 1999). Conversely, lowering neuronal excitability increases excitatory synaptic input (Turrigiano et al., 1998). Thus, homeostatic mechanisms compensate a lack of excitatory inputs by increasing intrinsic neuronal excitability, and vice versa. The $\mathrm{R} 552 \mathrm{H}$ mutation in Foxp2 decreases both excitatory inputs and intrinsic excitability, indicating that the homeostatic control of neuronal gain is disrupted.

\section{Relevance for cortical activity}

A concurrent decrease in excitatory input and neuronal gain in cortical Layer VI is susceptible to alter cortical function. Layer VI cortico-thalamic neurons send collaterals to deep cortical layers in addition to their axonal projection onto thalamic nuclei (Thomson, 2010). Pharmacological experiments in visual cortex 
in vivo revealed that Layer VI neurons predominantly recruit inhibitory networks that control "end inhibition" in Layer IV, i.e., the propensity of some neurons to respond more strongly to short stimuli than to long ones (Bolz and Gilbert, 1986). More recent studies using optogenetics showed that the selective activation of Layer VI cortico-thalamic neurons recruits fast-spiking inhibitory interneurons to modulate the strength of cortical responses in all cortical layers (Olsen et al., 2012; Bortone et al., 2014). In addition, Layer VI cortico-thalamic neurons exert a suppressive effect on the thalamus, via their projection to the thalamus reticular nucleus which exclusively consists of inhibitory neurons (Olsen et al., 2012). While these studies were performed in visual cortex, the conservation of basic connectivity patterns in different cortices suggests that the recruitment of cortical Foxp2+ neurons tends to decrease upper cortex activity and, to a lesser extent, thalamic activity. Therefore, our findings suggest that loss-of-function Foxp2 mutations promote the excitability of upper cortical layers and thalamic nuclei, which may be relevant for the pathologic consequences of loss-of-function Foxp2 mutations.

\section{References}

Bekkers JM (2000) Properties of voltage-gated potassium currents in nucleated patches from large layer 5 cortical pyramidal neurons of the rat. J Physiol 525:593-609.

Bolz J, Gilbert CD (1986) Generation of end-inhibition in the visual cortex via interlaminar connections. Nature 320:362-365.

Bortone DS, Olsen SR, Scanziani M (2014) Translaminar inhibitory cells recruited by layer 6 corticothalamic neurons suppress visual cortex. Neuron 82:474-485.

Chen YC, Kuo HY, Bornschein U, Takahashi H, Chen SY, Lu KM, Yang HY, Chen GM, Lin JR, Lee YH, Chou YC, Cheng SJ, Chien CT, Enard W, Hevers W, Pääbo S, Graybiel AM, Liu FC (2016) Foxp2 controls synaptic wiring of corticostriatal circuits and vocal communication by opposing Mef2c. Nat Neurosci 19:1513-1522.

Desai NS, Rutherford LC, Turrigiano GG (1999) Plasticity in the intrinsic excitability of cortical pyramidal neurons. Nat Neurosci 2:515-520.

Doyle JP, Dougherty JD, Heiman M, Schmidt EF, Stevens TR, Ma G, Bupp S, Shrestha P, Shah RD, Doughty ML, Gong S, Greengard P, Heintz N (2008) Application of a translational profiling approach for the comparative analysis of CNS cell types. Cell 135:749-762.

Ehret G (1997) The auditory cortex. J Comp Physiol A Neuroethol Sens Neural Behav Physiol 181:547-557.

Enard W, Przeworski M, Fisher SE, Lai CS, Wiebe V, Kitano T, Monaco AP, Pääbo S (2002) Molecular evolution of FOXP2, a gene involved in speech and language. Nature 418:869-872.

Enard W, Gehre S, Hammerschmidt K, Hölter SM, Blass T, Somel M, Brückner MK, Schreiweis C, Winter C, Sohr R, Becker L, Wiebe V, Nickel B, Giger T, Müller U, Groszer M, Adler T, Aguilar A, Bolle I, Calzada-Wack J, et al. (2009) A humanized version of Foxp2 affects cortico-basal ganglia circuits in mice. Cell 137:961-971.

Ferland RJ, Cherry TJ, Preware PO, Morrisey EE, Walsh CA (2003) Characterization of Foxp2 and Foxp1 mRNA and protein in the developing and mature brain. J Comp Neurol 460:266-279.

French CA, Fisher SE (2014) What can mice tell us about Foxp2 function? Curr Opin Neurobiol 28:72-79.

French CA, Vinueza Veloz MF, Zhou K, Peter S, Fisher SE, Costa RM, De Zeeuw CI (2019) Differential effects of Foxp2 disruption in distinct motor circuits. Mol Psychiatry 24:447-462.

García-López P, García-Marín V, Freire M (2006) Three-dimensional reconstruction and quantitative study of a pyramidal cell of a Cajal histological preparation. J Neurosci 26:11249-11252.

Gong S, Doughty M, Harbaugh CR, Cummins A, Hatten ME, Heintz N, Gerfen CR (2007) Targeting Cre recombinase to specific neuron populations with bacterial artificial chromosome constructs. J Neurosci 27:9817-9823

Gonzalez JC, Epps SA, Markwardt SJ, Wadiche JI, Overstreet-Wadiche L (2018) Constitutive and synaptic activation of GIRK channels differentiates mature and newborn dentate granule cells. J Neurosci 38:6513-6526.
Groszer M, Keays DA, Deacon RMJ, de Bono JP, Prasad-Mulcare S, Gaub S, Baum MG, French CA, Nicod J, Coventry JA, Enard W, Fray M, Brown SDM, Nolan PM, Pääbo S, Channon KM, Costa RM, Eilers J, Ehret G, Rawlins JNP, et al. (2008) Impaired synaptic plasticity and motor learning in mice with a point mutation implicated in human speech deficits. Curr Biol 18:354-362.

Haesler S, Wada K, Nshdejan A, Morrisey EE, Lints T, Jarvis ED, Scharff C (2004) FoxP2 expression in avian vocal learners and non-learners. J Neurosci 24:3164-3175.

Hearing M, Kotecki L, Marron Fernandez de Velasco E, Fajardo-Serrano A, Chung HJ, Luján R, Wickman K (2013) Repeated cocaine weakens GABA(B)-Girk signaling in layer 5/6 pyramidal neurons in the prelimbic cortex. Neuron 80:159-170.

Huang W, Zhou Z, Asrar S, Henkelman M, Xie W, Jia Z (2011) p21Activated kinases 1 and 3 control brain size through coordinating neuronal complexity and synaptic properties. Mol Cell Biol 31:388-403.

Kaas JH (2005) From mice to men: the evolution of the large, complex human brain. J Biosci 30:155-165.

Kast RJ, Lanjewar AL, Smith CD, Levitt P (2019) FOXP2 exhibits projection neuron class specific expression, but is not required for multiple aspects of cortical histogenesis. Elife 8 .

Kuhl PK (2010) Brain mechanisms in early language acquisition. Neuron 67:713-727.

Kurt S, Groszer M, Fisher SE, Ehret G (2009) Modified sound-evoked brainstem potentials in Foxp2 mutant mice. Brain Res 1289:30-36.

Lai CS, Fisher SE, Hurst JA, Vargha-Khadem F, Monaco AP (2001) A forkhead-domain gene is mutated in a severe speech and language disorder. Nature 413:519-523.

Le Meur N, Holder-Espinasse M, Jaillard S, Goldenberg A, Joriot S, AmatiBonneau P, Guichet A, Barth M, Charollais A, Journel H, Auvin S, Boucher C, Kerckaert JP, David V, Manouvrier-Hanu S, Saugier-Veber P, Frébourg T, Dubourg C, Andrieux J, Bonneau D (2010) MEF2C haploinsufficiency caused by either microdeletion of the $5 \mathrm{q} 14.3$ region or mutation is responsible for severe mental retardation with stereotypic movements, epilepsy and/or cerebral malformations. J Med Genet 47: $22-29$.

Liégeois F, Baldeweg T, Connelly A, Gadian DG, Mishkin M, VarghaKhadem F (2003) Language fMRI abnormalities associated with FOXP2 gene mutation. Nat Neurosci 6:1230-1237.

Luján R, Maylie J, Adelman JP (2009) New sites of action for GIRK and SK channels. Nat Rev Neurosci 10:475-480.

Lüscher C, Slesinger PA (2010) Emerging roles for G protein-gated inwardly rectifying potassium (GIRK) channels in health and disease. Nat Rev Neurosci 11:301-315.

Medvedeva VP, Rieger MA, Vieth B, Mombereau C, Ziegenhain C, Ghosh T, Cressant A, Enard W, Granon S, Dougherty JD, Groszer M (2019) Altered social behavior in mice carrying a cortical Foxp2 deletion. Hum Mol Genet 28:701-717.

Meeks JP, Mennerick S (2007) Action potential initiation and propagation in CA3 pyramidal axons. J Neurophysiol 97:3460-3472.

Megías M, Emri Z, Freund TF, Gulyás AI (2001) Total number and distribution of inhibitory and excitatory synapses on hippocampal CA1 pyramidal cells. Neuroscience 102:527-540.

Mukherjee RS, McBride EW, Beinborn M, Dunlap K, Kopin AS (2006) Point mutations in either subunit of the GABAB receptor confer constitutive activity to the heterodimer. Mol Pharmacol 70:1406-1413.

Naeve GS, Ramakrishnan M, Kramer R, Hevroni D, Citri Y, Theill LE (1997) Neuritin: a gene induced by neural activity and neurotrophins that promotes neuritogenesis. Proc Natl Acad Sci USA 94:2648-2653.

Olsen SR, Bortone DS, Adesnik H, Scanziani M (2012) Gain control by layer six in cortical circuits of vision. Nature 483:47-52.

Peleg S, Varon D, Ivanina T, Dessauer CW, Dascal N (2002) G(alpha)(i) controls the gating of the $\mathrm{G}$ protein-activated $\mathrm{K}(+)$ channel, GIRK. Neuron 33:87-99.

Ramocki MB, Zoghbi HY (2008) Failure of neuronal homeostasis results in common neuropsychiatric phenotypes. Nature 455:912-918.

Reimers-Kipping S, Hevers W, Pääbo S, Enard W (2011) Humanized Foxp2 specifically affects cortico-basal ganglia circuits. Neuroscience 175:75-84.

Scanziani M (2000) GABA spillover activates postsynaptic GABA(B) receptors to control rhythmic hippocampal activity. Neuron 25:673-681. 
Scharff C, Petri J (2011) Evo-devo, deep homology and FoxP2: implications for the evolution of speech and language. Philos Trans R Soc Lond B Biol Sci 366:2124-2140.

Sia GM, Clem RL, Huganir RL (2013) The human language-associated gene SRPX2 regulates synapse formation and vocalization in mice. Science 342:987-991.

Spiteri E, Konopka G, Coppola G, Bomar J, Oldham M, Ou J, Vernes SC, Fisher SE, Ren B, Geschwind DH (2007) Identification of the transcriptional targets of FOXP2, a gene linked to speech and language, in developing human brain. Am J Hum Genet 81:1144-1157.

Sundberg SC, Lindström SH, Sanchez GM, Granseth B (2018) Cre-expressing neurons in visual cortex of Ntsr1-Cre GN220 mice are corticothalamic and are depolarized by acetylcholine. J Comp Neurol 526:120-132.

Tallal P, Miller SL, Bedi G, Byma G, Wang X, Nagarajan SS, Schreiner C, Jenkins WM, Merzenich MM (1996) Language comprehension in language-learning impaired children improved with acoustically modified speech. Science 271:81-84.

Tasic B, Menon V, Nguyen TN, Kim TK, Jarsky T, Yao Z, Levi B, Gray LT, Sorensen SA, Dolbeare T, Bertagnolli D, Goldy J, Shapovalova N, Parry S, Lee C, Smith K, Bernard A, Madisen L, Sunkin SM, Hawrylycz M, et al. (2016) Adult mouse cortical cell taxonomy revealed by single cell transcriptomics. Nat Neurosci 19:335-346.

Teramitsu I, Kudo LC, London SE, Geschwind DH, White SA (2004) Parallel FoxP1 and FoxP2 expression in songbird and human brain predicts functional interaction. J Neurosci 24:3152-3163.

Thomson AM (2010) Neocortical layer 6, a review. Front Neuroanat 4:13.

Turrigiano GG, Leslie KR, Desai NS, Rutherford LC, Nelson SB (1998) Activity-dependent scaling of quantal amplitude in neocortical neurons. Nature 391:892-896.

van Rhijn JR, Fisher SE, Vernes SC, Nadif Kasri N (2018) Foxp2 loss of function increases striatal direct pathway inhibition via increased GABA release. Brain Struct Funct 223:4211-4226.
Vargha-Khadem F, Gadian DG, Copp A, Mishkin M (2005) FOXP2 and the neuroanatomy of speech and language. Nat Rev Neurosci 6:131-138

Vélez-Fort M, Rousseau CV, Niedworok CJ, Wickersham IR, Rancz EA, Brown APY, Strom M, Margrie TW (2014) The stimulus selectivity and connectivity of layer six principal cells reveals cortical microcircuits underlying visual processing. Neuron 84:238.

Vernes SC, Nicod J, Elahi FM, Coventry JA, Kenny N, Coupe AM, Bird LE, Davies KE, Fisher SE (2006) Functional genetic analysis of mutations implicated in a human speech and language disorder. Hum Mol Genet 15:3154-3167.

Vernes SC, Spiteri E, Nicod J, Groszer M, Taylor JM, Davies KE, Geschwind DH, Fisher SE (2007) High-throughput analysis of promoter occupancy reveals direct neural targets of FOXP2, a gene mutated in speech and language disorders. Am J Hum Genet 81:12321250 .

Vernes SC, Oliver PL, Spiteri E, Lockstone HE, Puliyadi R, Taylor JM, Ho J, Mombereau C, Brewer A, Lowy E, Nicod J, Groszer M, Baban D, Sahgal N, Cazier JB, Ragoussis J, Davies KE, Geschwind DH, Fisher SE (2011) Foxp2 regulates gene networks implicated in neurite outgrowth in the developing brain. PLoS Genet 7:e1002145.

Waldmeier PC, Wicki P, Feldtrauer JJ, Mickel SJ, Bittiger H, Baumann PA (1994) GABA and glutamate release affected by GABAB receptor antagonists with similar potency: no evidence for pharmacologically different presynaptic receptors. Br J Pharmacol 113:1515-1521.

Watkins KE, Dronkers NF, Vargha-Khadem F (2002) Behavioural analysis of an inherited speech and language disorder: comparison with acquired aphasia. Brain 125:452-464

Yue Y, Widmer DA, Halladay AK, Cerretti DP, Wagner GC, Dreyer JL, Zhou R (1999) Specification of distinct dopaminergic neural pathways: roles of the Eph family receptor EphB1 and ligand ephrin-B2. J Neurosci 19:2090-2101. 